Article

\title{
Modelling and Design of Real-Time Energy Management Systems for Fuel Cell/Battery Electric Vehicles
}

\author{
Alessandro Serpi ${ }^{1,2, *(D)}$ and Mario Porru ${ }^{1,2}$ (D) \\ 1 Department of Electrical and Electronic Engineering, University of Cagliari, 09123 Cagliari, Italy \\ 2 Novel Electric Propulsion Systems, NEPSY srl, 09127 Cagliari, Italy \\ * Correspondence: alessandro.serpi@unica.it
}

Received: 7 August 2019; Accepted: 4 November 2019; Published: 8 November 2019

check for updates

\begin{abstract}
Modelling and design of real-time energy management systems for optimising the operating costs of a fuel cell/battery electric vehicle are presented in this paper. The proposed energy management system consists of optimally sharing the propulsion power demand between the fuel cell and battery by enabling them to support each other for operating cost minimisation. The optimisation is achieved through real-time minimisation of a cost function, which accounts for fuel cell and battery degradation, hydrogen consumption and charge sustaining costs. A detailed analysis of each term of the overall cost function is performed and presented, which enables the development of a real-time, advanced energy management system for improving a previously presented simplified version using more accurate modelling and by considering cost function minimisation over a given time horizon. The performance of the proposed advanced energy management system are verified through numerical simulations over different driving cycles; particularly, simulations were performed in MATLAB-Simulink by considering a hysteresis-based energy management system and both simplified and advanced versions of the proposed energy management system for comparison.
\end{abstract}

Keywords: batteries; cost function; electric vehicles; energy management; fuel cells; hybrid energy storage systems; hydrogen; optimisation

\section{Introduction}

Fuel cell/battery electric vehicles (FCBEVs) are a very promising solution for a more sustainable, future transportation system because fuel cells (FCs) are generally supplied by an on-board hydrogen tank, thus producing only water and heat at the tailpipe [1-3] and enabling longer driving ranges and faster refuelling compared to battery electric vehicles (BEVs). However, FCs are best exploited when they mainly supply constant-power loads and are much less suitable for coping with sudden and frequent power variations, such as those occurring during acceleration and braking. For this reason, FCs are generally employed with another energy storage system that is characterised by higher dynamic performances, such as batteries or supercapacitors, resulting in a hybrid energy storage system (HESS) that is characterised by high flexibility and the ability to cope with sudden power variations.

Regarding HESS, the main target is exploiting each energy storage system to the maximum extent. As a result, innovative HESS configurations are under development in order to reduce weight, volume and system complexity, while guaranteeing improved functionalities and management flexibility at the same time [4]. However, combining two or more energy storage systems in a hybrid configuration does not necessarily lead to improved functionalities that are enabled by the energy management system (EMS), which has to fulfil several tasks by splitting the power flow among the energy storage units properly in accordance with a given set of criteria $[5,6]$. In this regard, it is worth noting that 
EMS operation should be defined even at the HESS design stage in order to suitably size the energy storage units [7-10], especially in terms of power and energy capability. Furthermore, the EMS is mandatory to guarantee enhanced performance and efficiency over a wide range of operating conditions [11,12], as well as to avoid fast FC degradation because of frequent start-stop cycles [13]. Consequently, when the EMS is able to exploit the inherent features of each energy storage system effectively, the lifetime of each energy storage unit can be prolonged, resulting also in increased HESS efficiency and, thus, vehicle mileage and driving range.

Despite the additional ESS used with FC, a number of EMSs have been proposed for vehicular applications, which can be roughly classified as pure power split and optimisation-based EMSs [14]. Pure power split EMSs aim at sharing the power among the ESSs in accordance with one or more criteria that may derive from human expertise and/or specific targets. For example, a deterministic set of rules can be set up based on HESS features and operating conditions that are eventually improved by a fuzzy logic control approach [15-19]. Alternatively, filtering techniques allow splitting of the HESS power demand in accordance with different ESS dynamic performances, which are, for example, relatively low for FC and much higher for batteries or supercapacitors [20-22]. Model predictive control EMS, state machine EMS and trivial hysteresis-based EMS have been also proposed as valid alternatives to the above-mentioned pure power split methods [23-25]. Although pure power split EMSs are relatively simple and easy to implement, even in real-time, power splitting only may not ensure optimal performance, cost minimisation or durability maximisation, which may represent a key point because of the high cost of hydrogen, FC and batteries. For this reason, optimisation-based EMSs have been developed that aim at finding an optimal solution by minimising a suitable cost function. Several approaches can be employed to find the optimal solution [26,27], including dynamic programming [28-30], model predictive control [31], Pontryagin's Minimum Principle [32,33], nonlinear algorithms [34,35], and heuristic methods [36]. Among these, global optimisation approaches require prior information on the expected HESS power profile, as well as good knowledge of the system structure over the medium to long term [28-32,34]. Consequently, these approaches are especially suitable for smart grid applications [37,38], in which forecasting of expected generation and load power profiles are much more accurate and feasible than the vehicle driving pattern and load [39]. As opposed to global optimisation approaches, real-time approaches minimise a cost function through the knowledge of instantaneous parameter estimation and/or operating conditions only $[33,35,36]$. For instance, the equivalent consumption minimisation strategy has been proposed to reduce fuel consumption by turning a global optimisation problem into an instantaneous minimisation problem $[27,35]$. Therefore, real-time EMSs are generally less effective than global optimisation EMSs, but more feasible to implement when vehicular applications are concerned.

In this scenario, a real-time EMS for FCBEVs has been presented in [40]. In particular, a simplified EMS (S-EMS) was developed within the competition promoted by [41] with the aim of determining the most suitable power split between the FC and battery (B) for any given operating condition. Therefore, the FCBEV mathematical modelling and cost function presented in [41] were first considered. The cost function was suitably rearranged in order to split it into instantaneous and integrating parts, which enables the real-time optimisation of the cost function based on instantaneous FC and B current values only. The power split was achieved by a simplified FC-B power constraint, which significantly eases S-EMS implementation. The effectiveness of S-EMS has been proven by a simulation study performed in the MATLAB-Simulink environment and regards the comparison with a hysteresis-based EMS (H-EMS) over different driving cycles. Furthermore, S-EMS effectiveness was proved also by the fact that it ranked third in the above-mentioned competition [42], as it was able to achieve FCBEV operating cost minimisation near the optimal solution achieved by dynamic programming.

Given the very good performances achieved by S-EMS, a more detailed and extensive analysis of its design criteria and performances are presented in this paper by highlighting its most important strengths and weaknesses. Based on these, an advanced EMS (A-EMS) is proposed that aims at overcoming S-EMS weaknesses in order to further minimise FCBEV operating costs. In particular, 
A-EMS has been developed based on more accurate FCBEV mathematical modelling to achieve enhanced performances compared to S-EMS by reducing the number of assumptions made in the design stage. In addition, A-EMS determines the instantaneous power split between FC and B by considering the minimisation of the cost function over a given upcoming time interval by accounting for the state-of-charge of the B and upcoming voltage variations. These steps are performed to reduce the negative impact of increasing the B state-of-charge excessively, which cannot be prevented with S-EMS because the latter is based on only instantaneous minimisation. The comparison between S-EMS and A-EMS was performed by numerical simulations in MATLAB-Simulink, whose corresponding results are presented and discussed extensively.

The paper is structured as follows: mathematical modelling of the FCBEV propulsion system from [41] is resumed in Section 2 and the cost function is analysed in Section 3. Section 4 is devoted to both S-EMS and A-EMS, which are presented and extensively analysed. Simulation results are presented in Section 5 and discussed in Section 6. Section 7 concludes the paper, while all symbols employed are outlined in Appendix A (Tables A1 and A2).

\section{Modelling of the FCBEV Propulsion System}

The general overview of the FCBEV electric propulsion system is depicted in Figure 1 [41]; the FC is connected to the DC-link through a unidirectional boost converter, which enables proper coupling in terms of voltage and current ratings. Alternatively, B is coupled directly to the DC-link as there is no need for adapting its voltage and current capability to those of the DC-link. The DC-link supplies the DC/AC traction inverter, which, in turn, supplies the traction motor $(\mathrm{M})$ in accordance with its power demand and regenerative braking needs. Mathematical models of FC, B and M are fundamental to developing the EMS; therefore, although they have been already presented in [40,41], they are also briefly described.

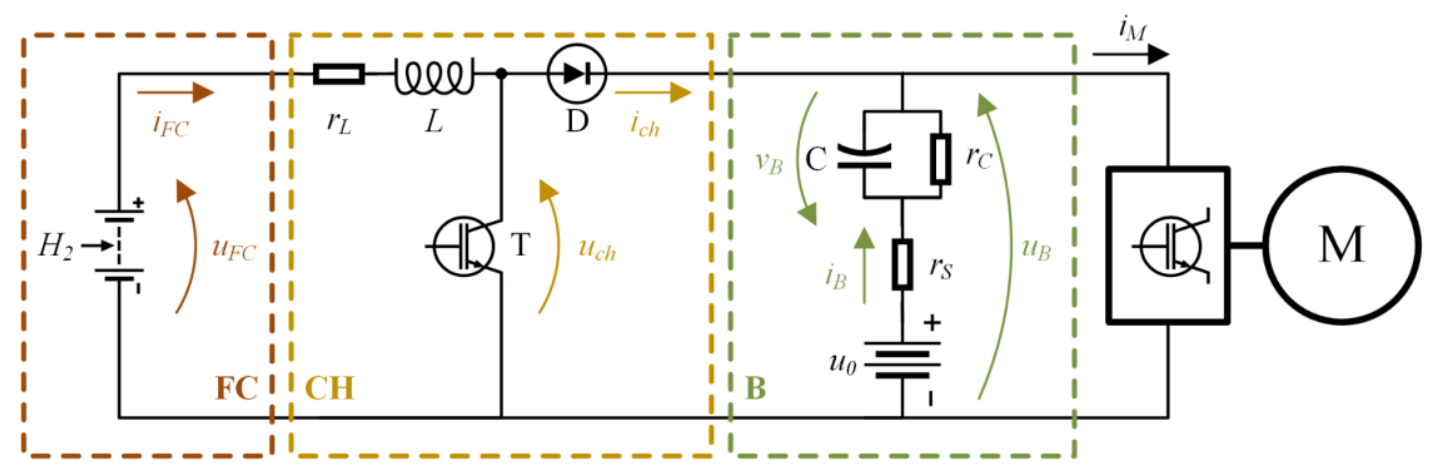

Figure 1. The FCBEV electric propulsion system: fuel cell (FC), boost converter (CH), battery (B), and traction motor $(\mathrm{M})$.

\subsection{Fuel Cell}

The FC is modelled as a current-dependent voltage source $\left(u_{\mathrm{FC}}\right)$ based on its static polarisation curve [41] with the following relationship:

$$
u_{\mathrm{FC}}=\sum_{k=0}^{3} a_{k} i_{\mathrm{FC}}^{k}
$$

in which $i_{\mathrm{FC}}$ denotes the FC current, while the coefficients $a_{k}$ are resumed in Table A2. Considering the boost converter, its average voltage equation can be expressed as:

$$
u_{\mathrm{FC}}=r_{L} i_{\mathrm{FC}}+L \frac{d i_{\mathrm{FC}}}{d t}+u_{\mathrm{CH}}
$$


in which $r_{L}$ and $L$ denote resistance and inductance of the boost converter inductor, while $u_{C H}$ denotes the average voltage across the switch $T$. The latter can be further expressed by means of the duty cycle of switch $\mathrm{T}$ and the DC-link voltage ( $d$ and $u_{\mathrm{B}}$ respectively), leading to:

$$
u_{\mathrm{CH}}=(1-d) \cdot u_{\mathrm{B}}
$$

Therefore, the average current of the boost converter $\left(i_{\mathrm{CH}}\right)$ can be computed by denoting the average efficiency of the boost converter by $\eta_{\mathrm{CH}}$ :

$$
i_{\mathrm{CH}}=(1-d) \eta_{\mathrm{CH}} i_{\mathrm{FC}} .
$$

Hence, based on (1)-(4), the FC and boost converter powers can be expressed respectively as:

$$
\begin{gathered}
p_{\mathrm{FC}}=u_{\mathrm{FC}} i_{\mathrm{FC}}=\sum_{k=0}^{3} a_{k} i_{\mathrm{FC}}^{k+1} \\
p_{\mathrm{CH}}=u_{\mathrm{B}}(1-d) \eta_{\mathrm{CH}} i_{\mathrm{FC}}=u_{\mathrm{CH}} \eta_{\mathrm{CH}} i_{\mathrm{FC}} .
\end{gathered}
$$

Considering the $\mathrm{H}_{2}$ consumption, this is assumed proportional to $i_{\mathrm{FC}}$ through the following relationship [41]:

$$
\dot{m}_{\mathrm{H}_{2}}=\gamma_{0}+\gamma_{1} i_{\mathrm{FC}}, i_{\mathrm{FC}}>0
$$

where the coefficients $\gamma_{0}$ and $\gamma_{1}$ are resumed in Table A2.

\subsection{Battery}

Battery is modelled as the equivalent circuit shown in Figure 1, whose parameters are outlined in Table A2 [41]. This circuit consists of a charge-dependent voltage source $\left(u_{0}\right)$, an equivalent series resistance $\left(r_{S}\right)$ and an RC parallel branch; in particular, $u_{0}$ depends on the B state-of-charge $\left(\varepsilon_{\mathrm{B}}\right)$ through the following relationship:

$$
u_{0}=\mu_{0}+\mu_{1} \varepsilon_{\mathrm{B}} .
$$

in which the coefficients $\mu_{0}$ and $\mu_{1}$ are summarized in Table A2. Furthermore, the B voltage and current equations are respectively:

$$
\begin{gathered}
u_{0}-r_{S} i_{\mathrm{B}}-v_{\mathrm{B}}=u_{\mathrm{B}} \\
C \frac{d v_{\mathrm{B}}}{d t}+\frac{v_{\mathrm{B}}}{r_{\mathrm{C}}}=i_{\mathrm{B}}
\end{gathered}
$$

where $i_{\mathrm{B}}$ is the overall $\mathrm{B}$ current, while $v_{\mathrm{B}}, r_{\mathrm{C}}$ and $C$ are the voltage, resistance and capacitance of the RC branch, respectively. Regarding $\varepsilon_{\mathrm{B}}$, this depends on $i_{\mathrm{B}}$ and on the $\mathrm{B}$ rated capacity $\left(Q_{\mathrm{B}}\right)$ through the following relationship:

$$
\frac{d \varepsilon_{\mathrm{B}}}{d t}=-\frac{i_{\mathrm{B}}}{Q_{\mathrm{B}}}
$$

\subsection{Traction Motor}

Considering a simplified steady-state model of $\mathrm{M}$, the power drawn at the DC-link is:

$$
p_{\mathrm{M}}=\left(\xi_{\mathrm{M}} F_{\mathrm{M}}+\varsigma_{\mathrm{M}}\left|F_{\mathrm{M}}\right|\right) \cdot v
$$

where $F_{M}$ denotes the $\mathrm{M}$ traction effort and $v$ is the vehicle speed. Furthermore, $\xi_{M}$ and $\varsigma_{M}$ are two a-dimensional coefficients that depend on the $\mathrm{M}$ efficiency $\left(\eta_{\mathrm{M}}\right)$ as:

$$
\xi_{\mathrm{M}}=\frac{1}{2}\left(\frac{1}{\eta_{\mathrm{M}}}+\eta_{\mathrm{M}}\right), \varsigma_{\mathrm{M}}=\frac{1}{2}\left(\frac{1}{\eta_{\mathrm{M}}}-\eta_{\mathrm{M}}\right) .
$$


In this regard, it is worth emphasising that $\eta_{M}$ varies with both $F_{M}$ and $v$ in accordance with the $M$ efficiency map [41]. The overall traction effort on vehicle wheels $\left(F_{T}\right)$ is thus:

$$
F_{T}=F_{\mathrm{M}}+F_{b}
$$

in which $F_{b}$ is the braking force exerted by mechanical braking devices. Therefore, $F_{b}$ is zero when $F_{T}$ is positive because no braking is needed. Otherwise $\left(F_{T}<0\right)$, regenerative braking may occur in accordance with the value of the regenerative braking coefficient $\left(k_{D}\right)$ :

$$
\left\{\begin{array}{l}
F_{\mathrm{M}}=k_{D} F_{T} \\
F_{b}=\left(1-k_{D}\right) F_{T}
\end{array}, F_{T}<0,0 \leq k_{D} \leq \frac{1}{2} .\right.
$$

Therefore, different $k_{D}$ values could be chosen depending on the FC usage and/or B charging needs.

\section{FCBEV Cost Function}

The EMS should be developed in order to minimise the following FCBEV cost function [41]:

$$
\Phi=\phi_{\mathrm{FC}}+\phi_{\mathrm{H}_{2}}+\phi_{\mathrm{B}}+\phi_{S T}
$$

in which $\phi_{\mathrm{FC}}$ and $\phi_{\mathrm{B}}$ account for FC and B degradation, $\phi_{\mathrm{H} 2}$ for the $\mathrm{H}_{2}$ consumption and $\phi_{S T}$ for the 'charge sustaining' cost:

$$
\begin{gathered}
\phi_{\mathrm{FC}}=c_{\mathrm{FC}}\left(n \Delta_{\mathrm{FC}}+k_{\mathrm{FC}} \int_{0}^{t}\left(1+\alpha\left(1-\frac{p_{\mathrm{FC}}}{P_{\mathrm{FC}}}\right)^{2}\right) d \tau\right) \\
\phi_{\mathrm{H}_{2}}=c_{\mathrm{H}_{2}} \int_{0}^{t} \dot{m}_{H_{2}} d \tau \\
\phi_{\mathrm{B}}=c_{\mathrm{B}} k_{\mathrm{B}} \int_{0}^{t}\left(1+\frac{13}{4}\left(1-\varepsilon_{\mathrm{B}}\right)^{2}\right)\left(1+\frac{\left|i_{\mathrm{B}}\right|}{2 I_{\mathrm{B}}}-\frac{i_{\mathrm{B}}}{20 I_{\mathrm{B}}}\right)\left|i_{\mathrm{B}}\right| d \tau \\
\phi_{S T}=p_{3} \varepsilon_{\mathrm{B}}^{3}+p_{2} \varepsilon_{\mathrm{B}}^{2}+p_{1} \varepsilon_{\mathrm{B}}+p_{0} .
\end{gathered}
$$

Considering (17)-(20), all of them come from [41], although the $\phi_{\mathrm{B}}$ expression is rearranged compared to the expression reported in [41] in order to make it more compact, while all coefficient values and meanings are summed up in Tables A1 and A2. Focusing on $\phi_{\mathrm{FC}}$ at first, it consists of a proportional and an integral term: the former accounts for FC degradation due to the number of starts and stops, while the latter estimates FC degradation due to usage. In this regard, minimum FC degradation is achieved by turning on FC once and running it at its rated power. Regarding $\phi_{\mathrm{H} 2}$, it is proportional to the overall $\mathrm{H}_{2}$ consumption, while $\phi_{\mathrm{B}}$ depends on both $\mathrm{B}$ actual state-of-charge and depth of charge/discharge; in this regard, $\mathrm{B}$ discharging $\left(i_{\mathrm{B}}<0\right)$ is weighted slightly more than $\mathrm{B}$ charging $\left(i_{\mathrm{B}}>0\right)$, as highlighted by the integral term of (19). Considering $\phi_{S T}$, it accounts for the cost of fully recharging B at the end of the driving cycle and at the best FC efficiency, as identified in [41].

Considering (16)-(20), $\Phi$ consists of both proportional and integral terms. Specifically, proportional terms account for FC start and stop degradation and charge sustaining costs, as highlighted in (17) and (20), respectively. Alternatively, integral terms account for FC and B degradation, as well as for $\mathrm{H}_{2}$ consumption. It is worth noting that the presence of proportional terms in (16) should be avoided as much as possible in the development of a real-time EMS. In particular, the rules of the competition promoted in [41] require that the EMS minimises $\Phi$ in real time for any given traction effort $F_{T}$ by selecting the most suitable combination of $k_{D}$ and $i_{\mathrm{FC}}$ without any prior information on the driving 
cycle. Consequently, it is not possible to plan the number of FC starts and stops, as well as minimise $\phi_{S T}$ at each time instant. Instead, it is possible for all of the integral terms of $\Phi$ because their minimisation can be carried out by referring to instantaneous values of $p_{\mathrm{M}}, k_{D}, i_{\mathrm{FC}}, i_{\mathrm{B}}$, and $\varepsilon_{\mathrm{B}}$ only.

The issues arising from proportional terms in (16) can be overcome by assuming that FC, once started, never stops; in addition, by combining (20) with (11) properly, $\phi_{S T}$ can be expressed as:

$$
\phi_{S T}=-\int_{0}^{t}\left(3 p_{3} \varepsilon_{\mathrm{B}}^{2}+2 p_{2} \varepsilon_{\mathrm{B}}+p_{1}\right) \frac{i_{\mathrm{B}}}{Q_{\mathrm{B}}} d \tau+\phi_{S T}\left(\varepsilon_{\mathrm{B}}^{(0)}\right) .
$$

As a result, $\Phi$ can be rearranged as:

$$
\Phi=\Phi_{0}+\int_{0}^{t} \varphi(\tau) d \tau
$$

in which $\Phi_{0}$ is defined as:

$$
\Phi_{0}=c_{\mathrm{FC}} n \Delta_{\mathrm{FC}}+\phi_{S T}\left(\varepsilon_{\mathrm{B}}^{(0)}\right)
$$

while the cost function $\varphi$ is:

$$
\varphi=c_{\mathrm{FC}} k_{\mathrm{FC}}\left(1+\alpha\left(1-\frac{p_{\mathrm{FC}}}{P_{\mathrm{FC}}}\right)^{2}\right)+c_{H_{2}}\left(\gamma_{0}+\gamma_{1} i_{\mathrm{FC}}\right)+c_{\mathrm{B}} k_{\mathrm{B}}\left(1+\frac{13}{4}\left(1-\varepsilon_{\mathrm{B}}\right)^{2}\right)\left(1+\frac{\left|\mathrm{i}_{\mathrm{B}}\right|}{2 l_{\mathrm{B}}}-\frac{i_{\mathrm{B}}}{20 l_{\mathrm{B}}}\right)\left|i_{\mathrm{B}}\right|-\left(3 p_{3} \varepsilon_{\mathrm{B}}^{2}+2 p_{2} \varepsilon_{\mathrm{B}}+p_{1}\right) \frac{i_{\mathrm{B}}}{Q_{\mathrm{B}}}
$$

which accounts for (7), (17)-(19) and (21). As a result, $\Phi$ minimisation can be performed by minimising its integral term $\varphi$ at every time instant for given $p_{\mathrm{M}}$ and $\varepsilon_{\mathrm{B}}$ values.

\section{Proposed Energy Management Systems}

\subsection{Simplified EMS}

The real-time S-EMS proposed in [40] has been developed based on the following assumptions:

- The FCBEV propulsion system is at steady-state operation and, thus, time derivatives of $i_{\mathrm{FC}}$ and $v_{\mathrm{B}}$ have been assumed equal to zero in (2) and (10), respectively:

$$
\frac{d i_{\mathrm{FC}}}{d t}=\frac{d v_{\mathrm{B}}}{d t}=0
$$

- The FC polarisation curve is approximated by a linear function of $i_{F C}$ :

$$
u_{\mathrm{FC}} \cong \alpha_{0}-\alpha_{1} i_{\mathrm{FC}}
$$

- $\quad \varepsilon_{\mathrm{B}}$ is considered an input of the EMS, like $p_{\mathrm{M}}$, because it is not possible to plan any $\varepsilon_{\mathrm{B}}$ evolution due to the knowledge of only instantaneous $i_{\mathrm{B}}$ values.

Therefore, the power balance at the DC-link must be considered first as:

$$
p_{\mathrm{M}}=p_{\mathrm{CH}}+p_{\mathrm{B}}
$$

in which $p_{\mathrm{CH}}$ is expressed by (6), while $p_{\mathrm{B}}$ is the $\mathrm{B}$ power that can be expressed based on (9) as:

$$
p_{\mathrm{B}}=u_{\mathrm{B}} i_{\mathrm{B}}=\left(u_{0}-v_{\mathrm{B}}-r_{\mathrm{S}} i_{\mathrm{B}}\right) i_{\mathrm{B}} .
$$


In particular, (27) enables determining $i_{\mathrm{FC}}$ and $i_{\mathrm{B}}$ as a function of $p_{\mathrm{M}}$ because both FC and $\mathrm{B}$ currents contribute to $p_{\mathrm{M}}$ and, thus, to the traction effort $F_{T}$ that must be achieved. Hence, considering (2) and (10), the assumption of being at steady-state operation leads to:

$$
\begin{gathered}
u_{\mathrm{CH}}=u_{\mathrm{FC}}-r_{L} i_{\mathrm{FC}} \\
v_{\mathrm{B}}=r_{\mathrm{C}} i_{\mathrm{B}} .
\end{gathered}
$$

As a result, by substituting (26) in (29) and, in turn, (29) in (6), the boost converter power can be expressed as:

$$
p_{\mathrm{CH}} \cong \eta_{\mathrm{CH}} i_{\mathrm{FC}}\left(\alpha_{0}-\left(r_{L}+\alpha_{1}\right) i_{\mathrm{FC}}\right) .
$$

The substitution of (30) in (28) yields:

$$
p_{\mathrm{B}}=\left(u_{0}-\left(r_{S}+r_{C}\right) i_{\mathrm{B}}\right) i_{\mathrm{B}} .
$$

As a result, the substitution of (31) and (32) in (27) makes the latter a conic as it depends on both quadratic functions of $i_{\mathrm{FC}}$ and $i_{\mathrm{B}}$ because (1) is simplified as (26), thus highlighting the usefulness of the assumption. Therefore, based on previous considerations, (27) can be rearranged as:

$$
\frac{1}{a_{\mathrm{FC}}^{2}}\left(i_{\mathrm{FC}}-c_{\mathrm{FC}}\right)^{2}+\frac{1}{a_{\mathrm{B}}^{2}}\left(i_{\mathrm{B}}-c_{\mathrm{B}}\right)^{2}=r^{2}
$$

in which:

$$
a_{\mathrm{FC}}=\sqrt{r_{S}+r_{C}}, a_{\mathrm{B}}=\sqrt{\eta_{\mathrm{CH}}\left(\alpha_{1}+r_{L}\right)}, c_{\mathrm{FC}}=\frac{1}{2} \frac{\alpha_{0}}{\frac{\eta_{C H}\left(\alpha_{1}+r_{L}\right)}{2}}, c_{\mathrm{B}}=\frac{1}{2} \frac{u_{0}}{r_{S}+r_{C}}, r=\sqrt{\frac{-p_{\mathrm{M}}}{\eta_{C H}\left(\alpha_{1}+r_{L}\right)\left(r_{S}+r_{C}\right)}+\frac{c_{\mathrm{FC}}^{2}}{r_{S}+r_{C}}+\frac{c_{\mathrm{B}}^{2}}{\eta_{C H}\left(\alpha_{1}+r_{L}\right)}} .
$$

Referring to the $\left(i_{\mathrm{FC}}, i_{\mathrm{B}}\right)$ plane, (33) defines a family of ellipses, as highlighted in Figure 2. In particular, ellipse centres depend on some FC and B parameters/variables, while ellipse radii depend also on the traction power $p_{\mathrm{M}}$. Consequently, all of the $i_{\mathrm{FC}}$ and $i_{\mathrm{B}}$ pairs of values that satisfy (33) are:

$$
\left\{\begin{array}{l}
i_{\mathrm{FC}}=c_{\mathrm{FC}}+a_{\mathrm{FC}} r \cdot \cos \vartheta \\
i_{\mathrm{B}}=c_{\mathrm{B}}+a_{\mathrm{B}} r \cdot \sin \vartheta
\end{array}, \vartheta \in\left[\vartheta_{\min }, \vartheta_{\max }\right]\right.
$$

in which parameter $\vartheta$ is constrained by $\vartheta_{\min }$ and $\vartheta_{\max }$ that depends on the minimum and maximum value of $i_{\mathrm{FC}}$, respectively.

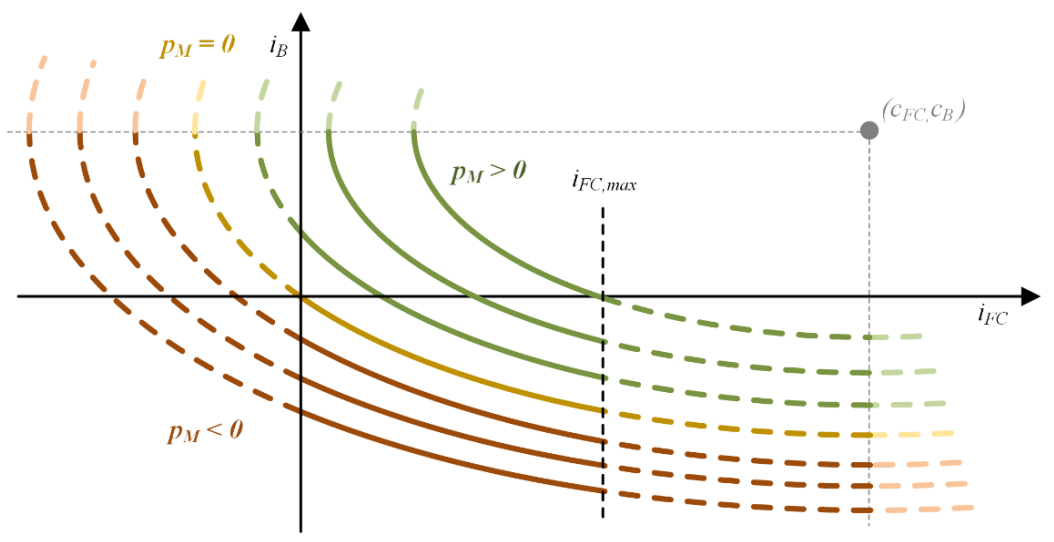

Figure 2. Constant $p_{\mathrm{M}}$ loci.

Therefore, by substituting (35) in (24), $\varphi$ minimisation can be achieved with respect to $\vartheta$, as shown in Figures 3-5. In particular, nine different cases have been considered that correspond to different $\left(p_{\mathrm{M}}, \varepsilon_{\mathrm{B}}\right)$ pairs of values. Furthermore, just the integral parts of each cost function have been depicted 
( $\varphi_{x}$ instead of $\phi_{x}$ ) and as a function of $i_{\mathrm{FC}}$ instead of $\vartheta$ for convenience. A first overview of these figures reveals that $\varphi_{\mathrm{B}}$ and, especially, $\varphi_{\mathrm{FC}}$ have relatively small values compared to both $\varphi_{\mathrm{H} 2}$ and $\varphi_{S T}$. Furthermore, $\varphi_{\mathrm{H} 2}$ is always positive and increases with $i_{\mathrm{FC}}$ due to their linear relationship highlighted in (24). Nearly the opposite occurs for $\varphi_{S T}$; it is generally negative and always decreases with $i_{\mathrm{FC}}$.
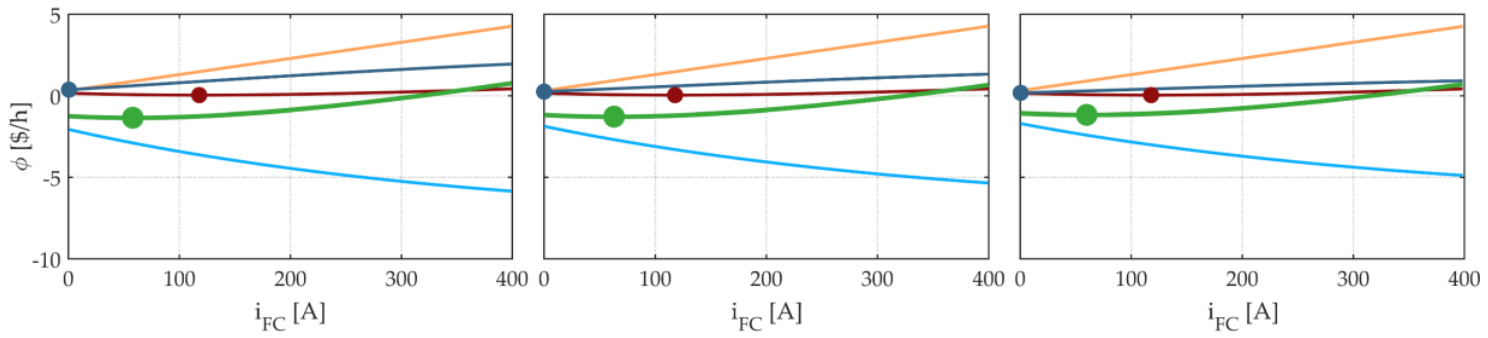

Figure 3. Evolution of the cost functions with $i_{\mathrm{FC}}$ at $p_{\mathrm{M}}=-8 \mathrm{~kW}$ and $\varepsilon_{\mathrm{B}}=0.3$ (left), 0.5 (middle) and 0.7 (right), in which the minimum value of some curves has been highlighted by a dot: $\varphi_{\mathrm{FC}}$ (red), $\varphi_{H 2}$ (orange), $\varphi_{\mathrm{B}}$ (blue), $\varphi_{S T}$ (cyan), and $\varphi$ (green).
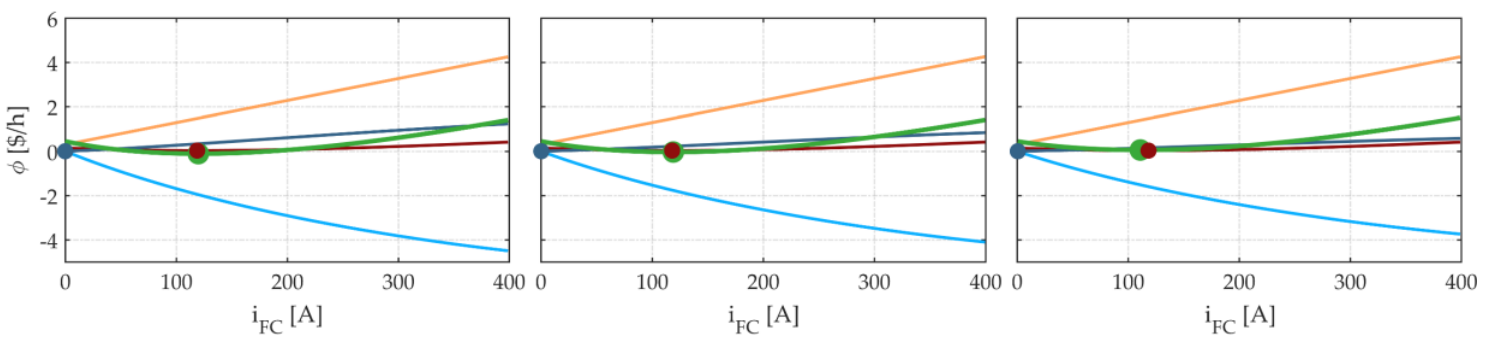

Figure 4. Evolution of the cost functions with $i_{\mathrm{FC}}$ at $p_{\mathrm{M}}=0 \mathrm{~kW}$ and $\varepsilon_{\mathrm{B}}=0.3$ (left), 0.5 (middle) and 0.7 (right), in which the minimum value of some curves has been highlighted by a dot: $\varphi_{\mathrm{FC}}$ (red), $\varphi_{\mathrm{H} 2}$ (orange), $\varphi_{\mathrm{B}}$ (blue), $\varphi_{S T}$ (cyan), and $\varphi$ (green).
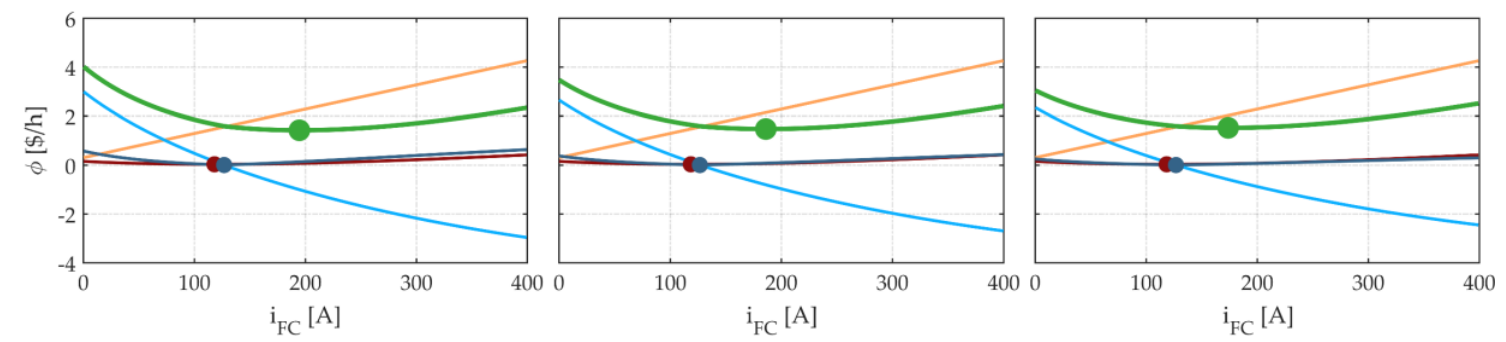

Figure 5. Evolution of the cost functions with $i_{\mathrm{FC}}$ at $p_{\mathrm{M}}=8 \mathrm{~kW}$ and $\varepsilon_{\mathrm{B}}=0.3$ (left), 0.5 (middle) and 0.7 (right), in which the minimum value of some curves has been highlighted by a dot: $\varphi_{\mathrm{FC}}$ (red), $\varphi_{\mathrm{H} 2}$ (orange), $\varphi_{\mathrm{B}}$ (blue), $\varphi_{S T}$ (cyan), and $\varphi$ (green).

Focusing on the cases of $p_{\mathrm{M}}=-8 \mathrm{~kW}$ first (Figure 3), the optimal $i_{\mathrm{FC}}$ value is relatively low (approximately $60 \mathrm{~A}$ ), especially if compared with the value that minimises $\varphi_{F C}$ (approximately $120 \mathrm{~A}$ ) $\mathrm{B}$ is expected to be recharged through regenerative braking, therefore $i_{\mathrm{FC}}$ has to be reduced properly in order to avoid $\mathrm{B}$ overcharging and, thus causing excessive $\mathrm{B}$ degradation and $\mathrm{H}_{2}$ consumption. This following consideration is valid: whatever the $\varepsilon_{\mathrm{B}}$ value, an increase has limited effects on both optimal $i_{\mathrm{FC}}$ and $\varphi$ values.

Considering the case of $p_{M}=0 \mathrm{~kW}$ (Figure 4), FC operates near its optimal value as optimal $i_{F C}$ is very close to the value that minimises $\varphi_{F C}$. Since no traction power is demanded, FC is just charging $\mathrm{B}$. This is convenient because $\mathrm{FC}$ degradation and $\mathrm{H}_{2}$ consumption costs are more than compensated by the reduction of the 'charge sustaining' cost until the optimal $i_{F C}$ is reached. Consequently, recharging $\mathrm{B}$ at an optimal rate is still profitable in this case, revealing the importance of $\varphi_{S T}$ in minimising $\varphi$ 
properly. Regarding $\varepsilon_{B}$, its increase determines the same effects as in the previous case: the optimal $i_{F C}$ and $\varphi$ values slightly vary with $\varepsilon_{B}$.

For the case of $p_{\mathrm{M}}=8 \mathrm{~kW}$ (Figure 5), the optimal $i_{\mathrm{FC}}$ is beyond the value that minimises $\varphi_{\mathrm{FC}}$ (170-190 A instead of about $120 \mathrm{~A}$ ), which is justified by the increased $p_{\mathrm{M}}$ value compared to the previous cases that forces $\mathrm{FC}$ to deliver all of the traction power and to recharge $\mathrm{B}$ at the same time.

It is worth noting that this outcome is not trivial, as it is expected that B supports FC in delivering the required traction power when it is relatively high. However, discharging B would lead to a very high 'charge sustaining' cost, resulting in weak $\varphi$ minimisation. For this reason, B discharging is convenient only when very high power is demanded. These considerations are valid for any $\varepsilon_{\mathrm{B}}$ value, whose increase has only minor effects, as previously mentioned.

The overall optimisation results achieved for any $\left(p_{\mathrm{M}}, \varepsilon_{\mathrm{B}}\right)$ pairs of values are depicted in Figures 6-9, in which $p_{\mathrm{M}}$ is expressed per unit with reference to a base value of $15 \mathrm{~kW}$. These figures are achieved by considering the optimal $\left(i_{\mathrm{FC}}, i_{\mathrm{B}}\right)$ pairs of values that minimise $\varphi$ at each operating condition. Therefore, Figure 6 confirms that $\varphi$ minimisation nearly coincides with $\varphi_{\mathrm{FC}}$ minimisation for any $\varepsilon_{\mathrm{B}}$ value when $p_{\mathrm{M}}$ is around zero. Furthermore, Figure 7 shows that $\mathrm{B}$ degradation is minimised within a relatively large part of the $\left(p_{\mathrm{M}}, \varepsilon_{\mathrm{B}}\right)$ plane, especially corresponding to high $p_{\mathrm{M}}$ values.
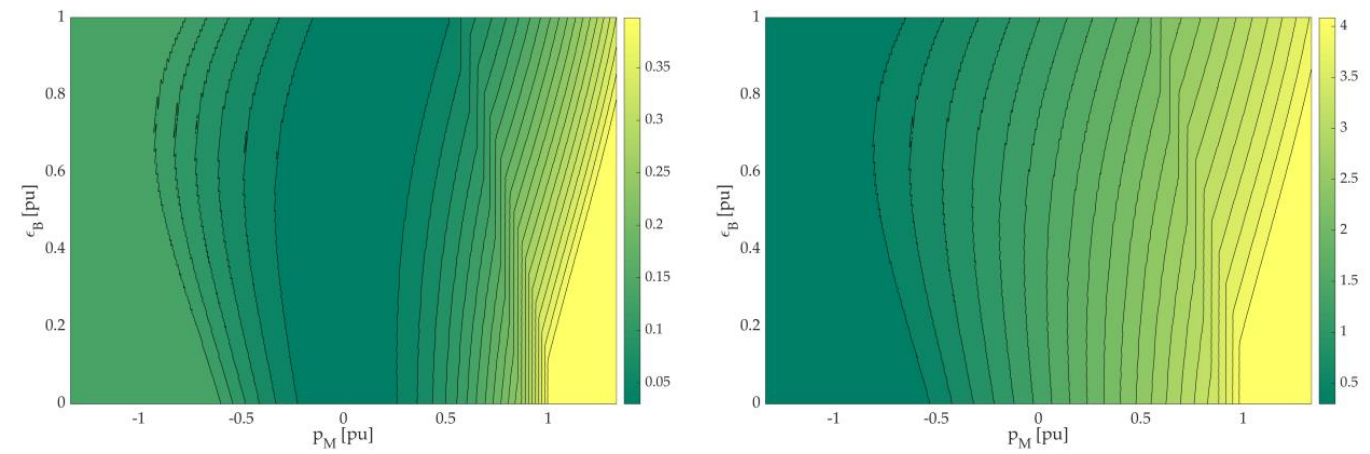

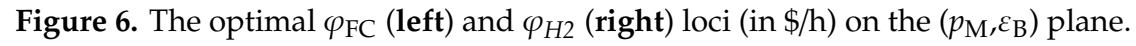
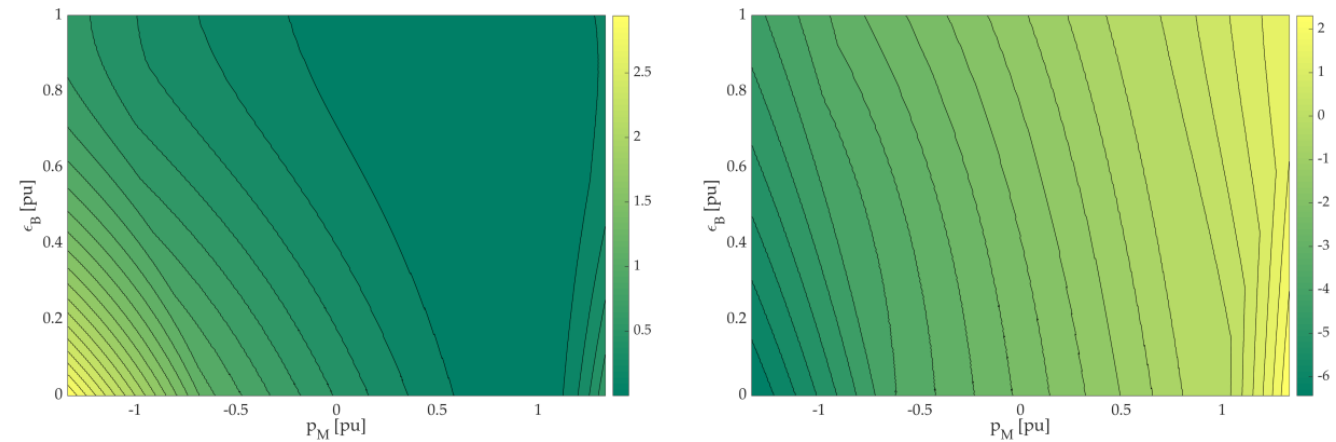

Figure 7. The optimal $\varphi_{\mathrm{B}}$ (left) and $\varphi_{S T}$ (right) loci (in $\$ / \mathrm{h}$ ) on the $\left(p_{\mathrm{M}}, \varepsilon_{\mathrm{B}}\right)$ plane.
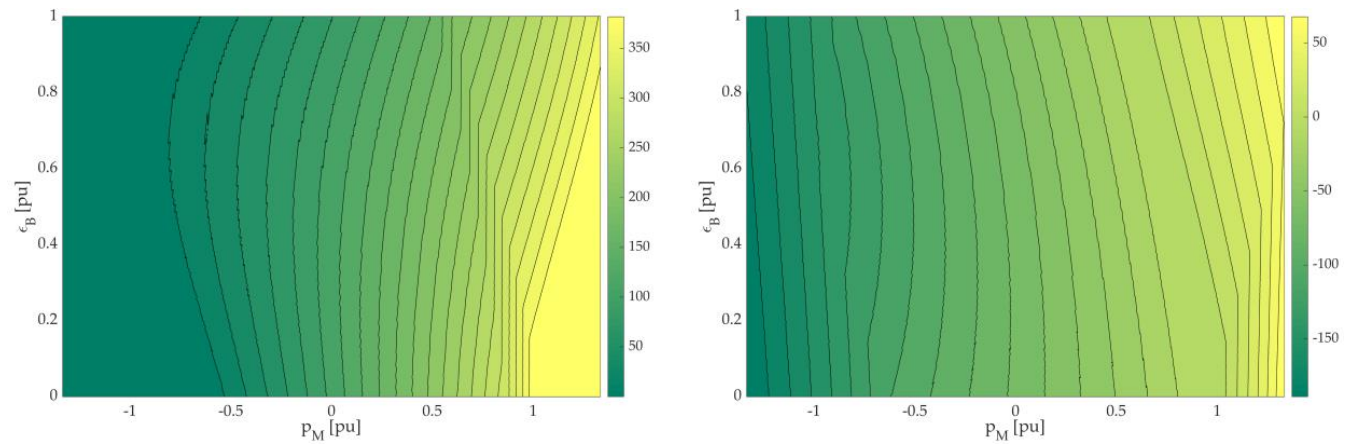

Figure 8. The optimal $i_{\mathrm{FC}}(\mathbf{l e f t})$ and $i_{\mathrm{B}}$ (right) loci (in A) on the $\left(p_{\mathrm{M}}, \varepsilon_{\mathrm{B}}\right)$ plane. 


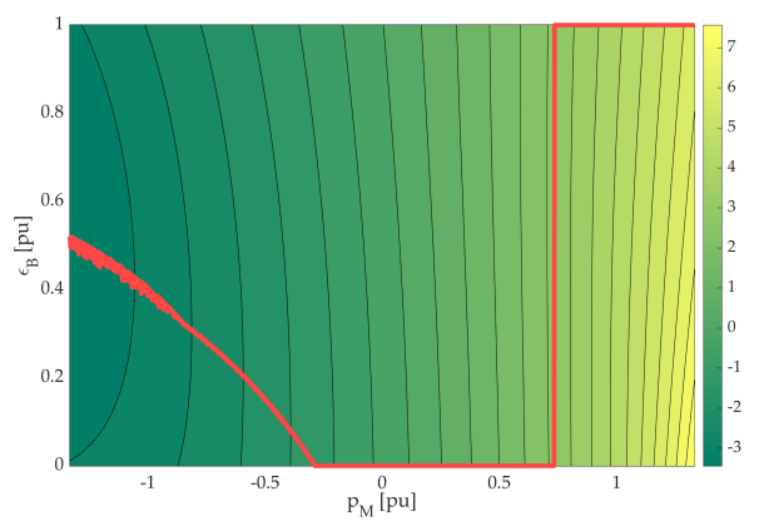

Figure 9. The optimal $\varphi$ locus (in $\$ / \mathrm{h})$ on the $\left(p_{\mathrm{M}}, \varepsilon_{\mathrm{B}}\right)$ plane, together with the optimal $\left(p_{\mathrm{M}}, \varepsilon_{\mathrm{B}}\right)$ trajectory (in red).

Regarding $\varphi_{\mathrm{H} 2}$ and $\varphi_{S T}$ (right panels of Figures 6 and 7), they both increase with $p_{\mathrm{M}}$, and $\varphi_{S T}$ is negative until very high $p_{\mathrm{M}}$ values are required, indicating that $\mathrm{B}$ should be recharged at most of FCBEV operating conditions, as confirmed by the optimal $i_{\mathrm{B}}$ values shown in Figure 8 . Alternatively, Figure 9 reveals that $k_{D}$ should always be maximised because $\varphi$ always decreases when $p_{\mathrm{M}}$ decreases.

Focusing on Figure 9 only, although instantaneous $\varphi$ minimisation surely benefits from $B$ recharging in correspondence with the majority of the FCBEV operating conditions, the $\varphi$ minimisation capability generally decreases as $\varepsilon_{\mathrm{B}}$ increases. In particular, the optimal $\left(p_{\mathrm{M}}, \varepsilon_{\mathrm{B}}\right)$ trajectory depicted in Figure 9 reveals that $\varepsilon_{\mathrm{B}}$ should be relatively low or even zero in order to achieve the minimum value of $\varphi$ when $p_{\mathrm{M}}$ is within a certain threshold (approximately $11 \mathrm{~kW}$ ). Beyond this threshold, $\varepsilon_{\mathrm{B}}$ should be maximum. Consequently, increasing $\varepsilon_{\mathrm{B}}$ may lead to unsuitable performances in terms of $\Phi$ minimisation, which is the final goal of the proposed S-EMS. This is especially true when relatively low power demands are of concern over a wide time horizon, which would result in unsuitable B charging. This disadvantage could be overcome by considering the variation of $\varepsilon_{\mathrm{B}}$ over an upcoming time horizon in order to achieve a suitable trade-off between instantaneous minimisation and reduced minimisation capability, as described in following subsection.

\subsection{Advanced EMS}

In order to improve the S-EMS, the assumptions made for its development and implementation should be removed or reduced as much as possible. In this regard, the relationship between $u_{\mathrm{FC}}$ and $i_{\mathrm{FC}}$ should not be further simplified, thus leading to a more accurate $\varphi$ assessment and minimisation. Consequently, by substituting (1) in (29) and, in turn, (29) in (6), the latter becomes:

$$
p_{\mathrm{CH}}=\eta_{\mathrm{CH}}\left(\sum_{k=0}^{3} a_{k} i_{\mathrm{FC}}^{k+1}-r_{L} i_{\mathrm{FC}}^{2}\right) .
$$

It is worth noting that it is still reasonable to consider the time derivative of $i_{\mathrm{FC}}$ equal to zero for EMS development purposes, thus preserving the validity of (29). However, similar considerations do not apply for $v_{\mathrm{B}}$ because of the very large time constant of the RC branch, as is easily detectable from numerical values reported in Table A2. Consequently, (30) leads to significant mismatches in estimating $B$ voltage and current values, which results in weak $\varphi$ assessment and minimisation. This drawback can be overcome by considering $v_{\mathrm{B}}$ as an EMS input, like the case of $\varepsilon_{\mathrm{B}}$ and $p_{\mathrm{M}}$.

Therefore, based on the previous considerations, (31) and (32) should be replaced by (28) and (36), and substituted into (27), leading to:

$$
p_{\mathrm{M}}=\eta_{\mathrm{CH}}\left(\sum_{k=0}^{3} a_{k} i_{\mathrm{FC}}^{k+1}-r_{L} i_{\mathrm{FC}}^{2}\right)+\left(u_{0}-v_{\mathrm{B}}-r_{S} i_{\mathrm{B}}\right) i_{\mathrm{B}} .
$$


Assuming $i_{F C}$ is the independent variable, $i_{\mathrm{B}}$ can be computed by solving (37) as:

$$
i_{\mathrm{B}}=b_{1}-\sqrt{b_{1}^{2}-b_{0}}, b_{1}=\frac{u_{0}-v_{\mathrm{B}}}{2 r_{\mathrm{S}}}, b_{0}=\frac{p_{\mathrm{M}}}{r_{S}}-\frac{\eta_{\mathrm{CH}}}{r_{S}}\left(\sum_{k=0}^{3} a_{k} i_{\mathrm{FC}}^{k+1}-r_{L} i_{\mathrm{FC}}^{2}\right)
$$

in which only the negative solution is considered because the other leads to excessive B usage without bringing any additional benefit. Therefore, by substituting (38) in (24), $\varphi$ can be minimised with respect to $i_{\mathrm{FC}}$ for any given $\left(p_{\mathrm{M},}, \varepsilon_{\mathrm{B}}, v_{\mathrm{B}}\right)$ triplet of values, as highlighted in Figures 10 and 11 . Additionally, in this case, $k_{D}$ should always be maximised because $\varphi$ always decreases when $p_{\mathrm{M}}$ decreases.
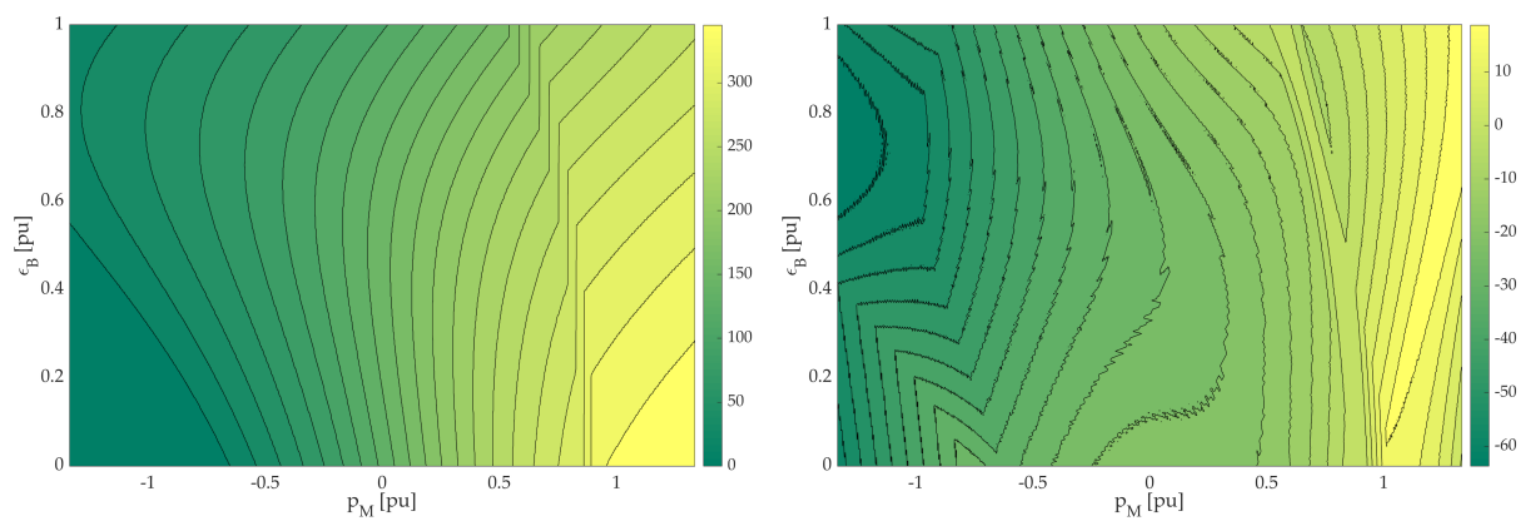

Figure 10. The optimal $i_{\mathrm{FC}}(\mathbf{l e f t})$ and $i_{\mathrm{B}}$ (right) loci (in $\left.\mathrm{A}\right)$ on the $\left(p_{\mathrm{M},}, \varepsilon_{\mathrm{B}}\right)$ plane for $v_{\mathrm{B}}=0$.

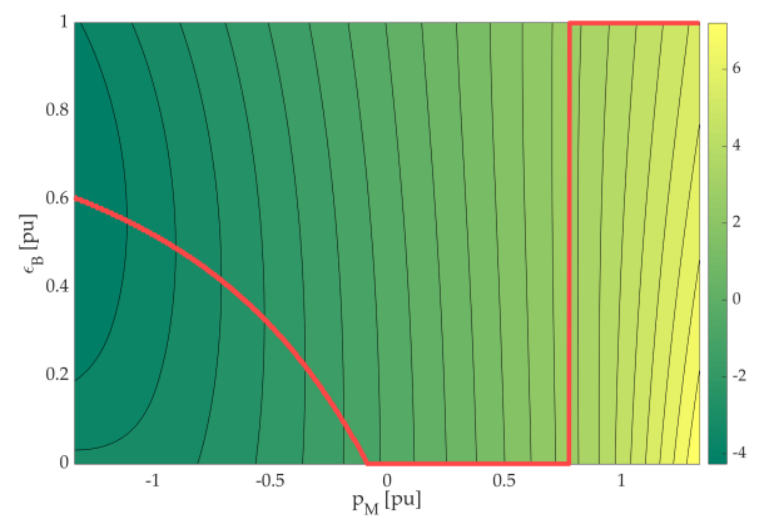

Figure 11. Optimal $\varphi$ locus (in $\$ / \mathrm{h}$ ) on the $\left(p_{\mathrm{M},}, \varepsilon_{\mathrm{B}}\right)$ plane and optimal $\left(p_{\mathrm{M}}, \varepsilon_{\mathrm{B}}\right)$ trajectory (in red, $\left.v_{\mathrm{B}}=0\right)$.

The comparison of Figures 8 and 9 with Figures 10 and 11 highlights the similar optimisation achieved by S-EMS and the proposed advanced EMS (A-EMS), with some differences. In particular, the comparison between Figures 9 and 11 illustrates that greater $\varepsilon_{\mathrm{B}}$ values are desirable for achieving better $\varphi$ minimisation in the low $p_{\mathrm{M}}$ range. However, the switching threshold of the optimal $\left(p_{\mathrm{M}}, \varepsilon_{\mathrm{B}}\right)$ trajectory moves from approximately $11 \mathrm{~kW}$ to approximately $11.6 \mathrm{~kW}$, resulting in the need for low $\varepsilon_{\mathrm{B}}$ values in a wider $p_{\mathrm{M}}$ range.

The differences between S-EMS and A-EMS are also highlighted in Figure 12, and were achieved by subtracting the optimal $i_{\mathrm{FC}}$ and $i_{\mathrm{B}}$ values obtained through S-EMS from those achieved by A-EMS for a given $v_{\mathrm{B}}$ value. Similarly, Figure 13 shows the differences between the $\varphi$ values obtained using optimal $\left(i_{\mathrm{FC}}, i_{\mathrm{B}}\right)$ pairs of values determined by S-EMS and A-EMS. Optimal $i_{\mathrm{FC}}\left(\right.$ or $\left.i_{\mathrm{B}}\right)$ is generally increased (or decreased) by A-EMS compared to S-EMS for relatively low $p_{\mathrm{M}}$ values, whereas the opposite occurs beyond a certain $p_{\mathrm{M}}$ threshold. In any case, A-EMS leads to better $\varphi$ minimisation for nearly all the $\left(p_{\mathrm{M},}, \varepsilon_{\mathrm{B}}\right)$ pairs of values; in this regard, worse performances seem to be achieved by A-EMS for low $\varepsilon_{\mathrm{B}}$ and high $p_{\mathrm{M}}$ values, as shown in Figure 13. However, these differences are due to 
the fact that the optimal $\left(i_{\mathrm{FC}}, i_{\mathrm{B}}\right)$ pairs of values achieved by S-EMS do not comply with (37), which is instead always satisfied by A-EMS at the cost of reduced $\varphi$ minimisation capability.
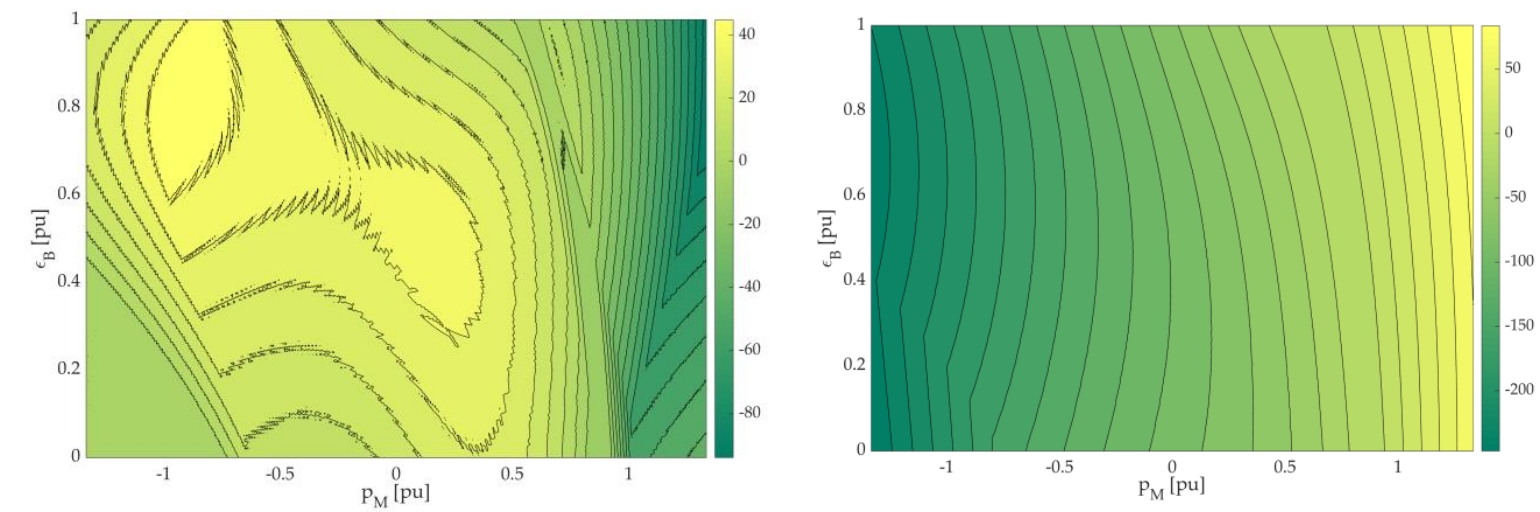

Figure 12. Differences between optimal $i_{F C}(\mathbf{l e f t})$ and $i_{B}$ (right) loci (in $\left.\mathrm{A}\right)$ on the $\left(p_{\mathrm{M}}, \varepsilon_{\mathrm{B}}\right)$ plane achieved by A-EMS for $v_{\mathrm{B}}=0$ and S-EMS.

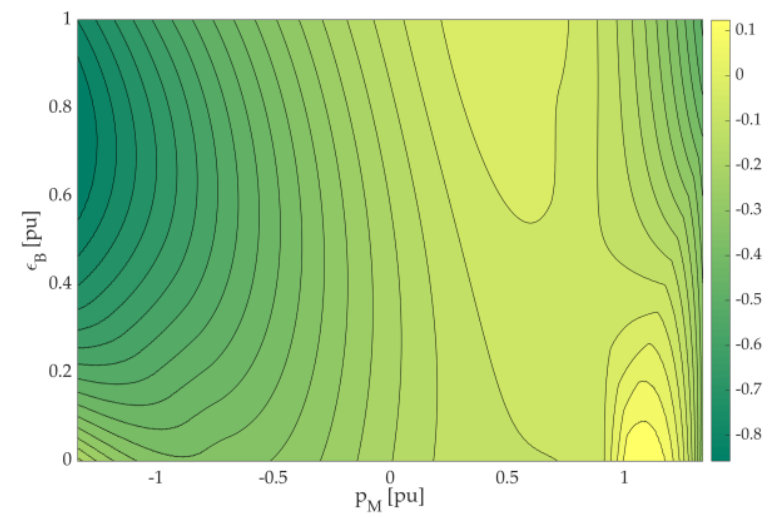

Figure 13. Differences between optimal $\varphi$ loci (in $\$ / \mathrm{h})$ on the $\left(p_{\mathrm{M}}, \varepsilon_{\mathrm{B}}\right)$ plane achieved by A-EMS for $v_{\mathrm{B}}=$ 0 and S-EMS.

Another improvement that can be introduced in designing the A-EMS consists of considering $\varepsilon_{\mathrm{B}}$ and $v_{\mathrm{B}}$ variations with $i_{\mathrm{B}}$ over an upcoming time interval $(\Delta T)$. Although assuming both $\varepsilon_{\mathrm{B}}$ and $v_{\mathrm{B}}$ constant seems quite reasonable, especially because no 'a priori' information is available on the $p_{\mathrm{M}}$ profile, the upcoming variation of $v_{\mathrm{B}}$ and, especially, of $\varepsilon_{\mathrm{B}}$ with $i_{\mathrm{B}}$ should be considered in minimising $\varphi$. This is important because both $\varepsilon_{\mathrm{B}}$ and $v_{\mathrm{B}}$ affect the upcoming values of $i_{\mathrm{B}}$ in accordance with (8) and (38). Therefore, instead of minimising the instantaneous value of $\varphi$, reference can be made to $\psi$, which is the average $\varphi$ approximation within the upcoming time interval $\Delta T$. This new cost function can be expressed as:

$$
\psi \cong \varphi+\frac{d \varphi}{d t} \frac{\Delta T}{2}
$$

in which the time derivative of $\varphi$ within $\Delta T$ can be computed analytically with respect to both $v_{\mathrm{B}}$ and $\varepsilon_{\mathrm{B}}$ as:

$$
\frac{d \varphi}{d t}=\left(\frac{\partial \varphi}{\partial \varepsilon_{\mathrm{B}}}+\frac{\partial \varphi}{\partial i_{\mathrm{B}}} \frac{\partial i_{\mathrm{B}}}{\partial \varepsilon_{\mathrm{B}}}\right) \frac{d \varepsilon_{\mathrm{B}}}{d t}+\frac{\partial \varphi}{\partial i_{\mathrm{B}}} \frac{\partial i_{\mathrm{B}}}{\partial v_{\mathrm{B}}} \frac{d v_{\mathrm{B}}}{d t} .
$$

As a result, minimising $\psi$ instead of $\varphi$ may improve $\Phi$ minimisation depending on the chosen $\Delta T$ value, as well as the FCBEV control system performances in terms of FC current tracking. 


\section{Simulation Results}

The performances achieved by both S-EMS and A-EMS were verified through numerical simulations in the MATLAB-Simulink environment. Three different driving cycles were considered, NEDC, WLTC and REAL, as well as the hysteresis-based EMS (H-EMS) provided by the competition promoted in [41] as a useful benchmark. H-EMS consists of turning on/off the FC depending on the value of $\varepsilon_{\mathrm{B}}$. If $\varepsilon_{\mathrm{B}}$ drops below a minimum threshold (0.4), $\mathrm{FC}$ is turned on at its maximum power $(16 \mathrm{~kW})$, thus recharging $B$ as fast as possible. As soon as $\varepsilon_{B}$ reaches a maximum threshold (0.7), FC is turned off and is not used any more until $\varepsilon_{\mathrm{B}}$ drops below the minimum threshold (0.4). As a result, just a hysteresis regulator is needed for implementing the H-EMS, which does not guarantee optimal power and energy evolutions. Instead, both S-EMS and A-EMS were implemented in accordance with the equivalent scheme depicted in Figure 14. A look-up table provides the most suitable $i_{\mathrm{FC}}$ reference values for any given $p_{M}, \varepsilon_{B}$ and, in the case of A-EMS, $v_{B}$ values. Regarding $i_{B}$, its reference value is computed automatically in order to comply with the reference traction effort imposed by the driving cycle. Alternatively, $k_{D}$ is always maximised on a condition in which $\varepsilon_{\mathrm{B}}$ is below a maximum threshold value (0.95); otherwise, $k_{D}$ is set to zero and $i_{\mathrm{FC}}$ is minimised in order to prevent $\mathrm{B}$ overcharging.

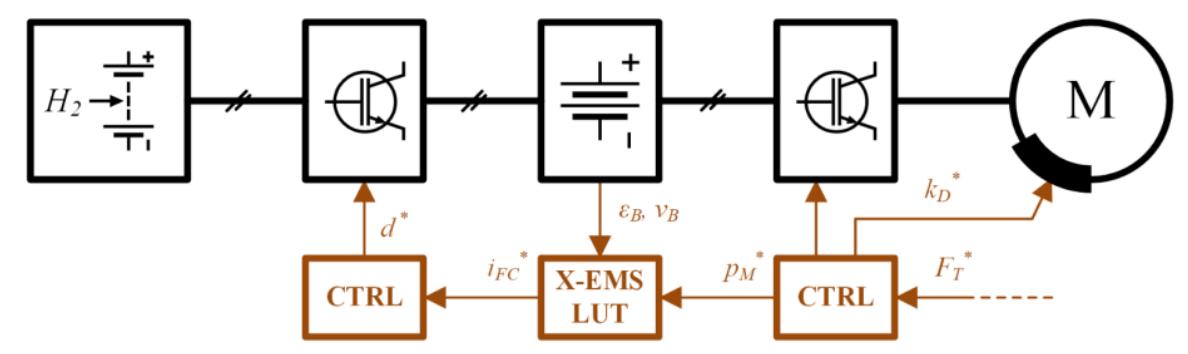

Figure 14. Schematic representation of either S-EMS or A-EMS.

Simulation results achieved by H-EMS and S-EMS over the NEDC driving cycle are reported in Figures 15 and 16. H-EMS turns on FC quite late compared to S-EMS, just when B is discharged to the minimum $\varepsilon_{\mathrm{B}}$ threshold. S-EMS turns on FC immediately at the start of the driving cycle in order to recharge $\mathrm{B}$ optimally in accordance with the $\varphi$ minimisation needs. Furthermore, the $p_{\mathrm{FC}}$ profile achieved by H-EMS is constant at an unoptimised value $(16 \mathrm{~kW})$, whereas that achieved by S-EMS slowly tracks $p_{M}$ in accordance with FC dynamic performances. In this regard, the reference $i_{\mathrm{FC}}$ profile is pre-filtered before sending it to the control system in order to prevent fast and sudden current variations. Consequently, B has to compensate for sudden power fluctuations due to vehicle accelerations and decelerations. As shown in Figures 15 and 16, the average FC power achieved by S-EMS is slightly greater than the required traction power because S-EMS aims at recharging B slowly during the driving cycle, whereas this task is mostly performed by H-EMS after the end of the driving cycle. Consequently, the final value of $\varepsilon_{\mathrm{B}}$ achieved by S-EMS is much greater than that achieved by H-EMS. This difference is related to the need to optimally minimise 'charge sustaining' costs, as highlighted in the bottom graph of Figure 16. 

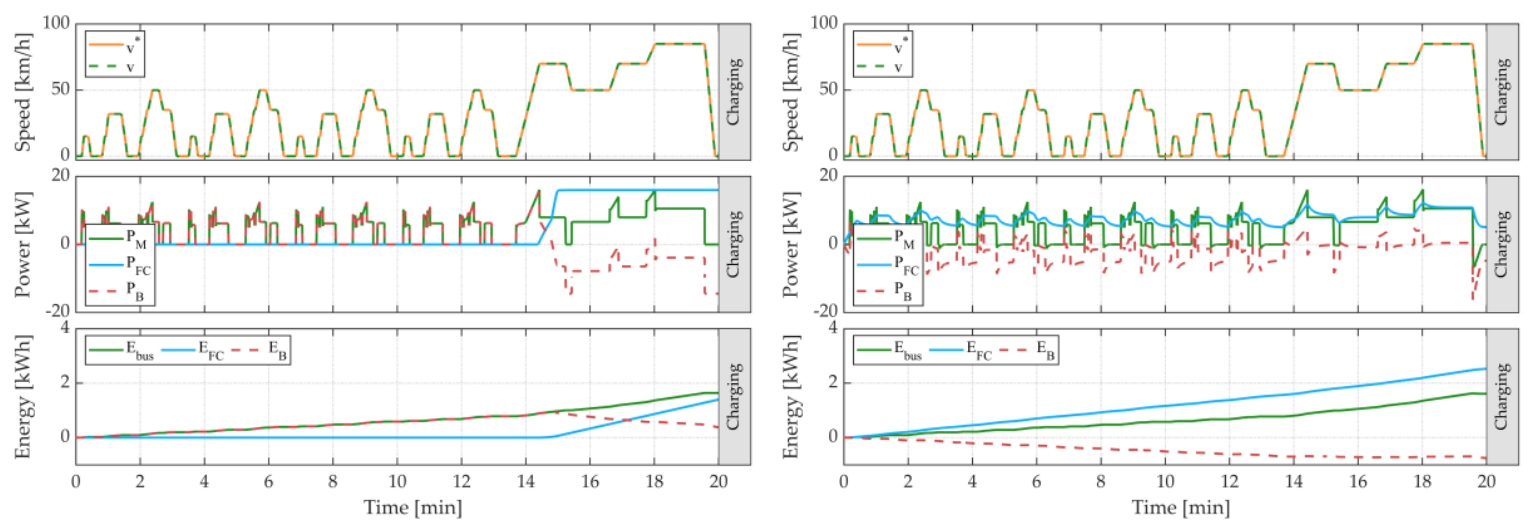

Figure 15. Powers and energies achieved over NEDC by H-EMS (left) and S-EMS (right).
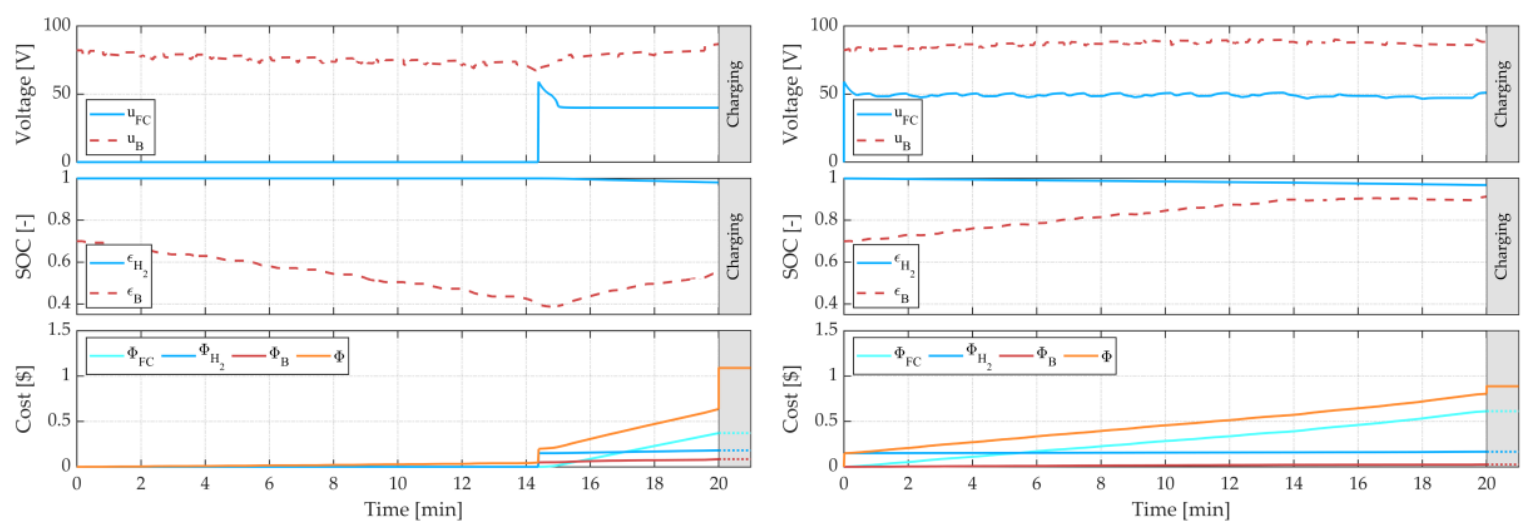

Figure 16. Voltages, state-of-charge and costs achieved over NEDC by H-EMS (left) and S-EMS (right).

Similar considerations are used for the WLTC driving cycle, as shown in Figures 17 and 18, with some differences. In particular, H-EMS turns off FC nearly at the end of the driving cycle. However, there is the need to turn on FC again after the end of the driving cycle because of B charging needs, resulting in high FC operating costs. Different considerations occur instead for the REAL driving cycle, as highlighted in Figures 19 and 20. Particularly, FC is never turned on by H-EMS due to the relatively short duration of this driving cycle, which prevents $B$ from reaching the minimum $\varepsilon_{B}$ threshold. However, even in this case, the turning on the FC turn occurs at the end of the driving cycle in order to comply with B charging reinstatement. As opposed to H-EMS, the proposed S-EMS turns on FC immediately; therefore, $p_{\mathrm{FC}}$ slowly tracks the highly variable $p_{\mathrm{M}}$ profile, while $\mathrm{B}$ successfully compensates for sudden and frequent $p_{\mathrm{M}}$ variations. Furthermore, as for both NEDC and WLTC driving cycles, the FC average power achieved by S-EMS slightly overcomes the average traction power demand in order to slowly recharge B during the driving cycle. 

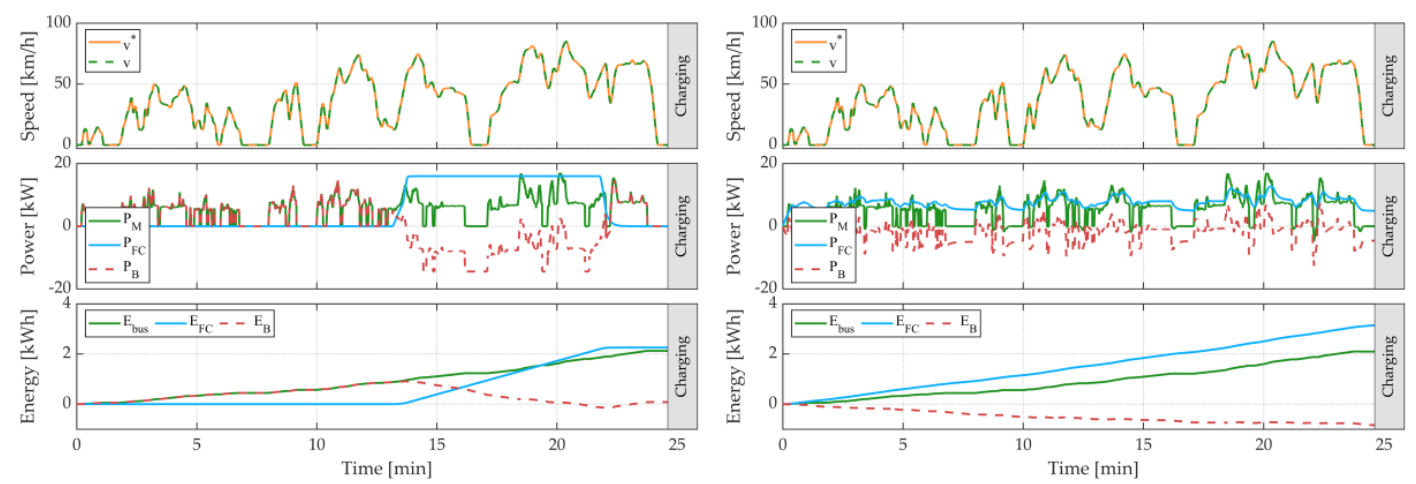

Figure 17. Powers and energies achieved over WLTC by H-EMS (left) and S-EMS (right).
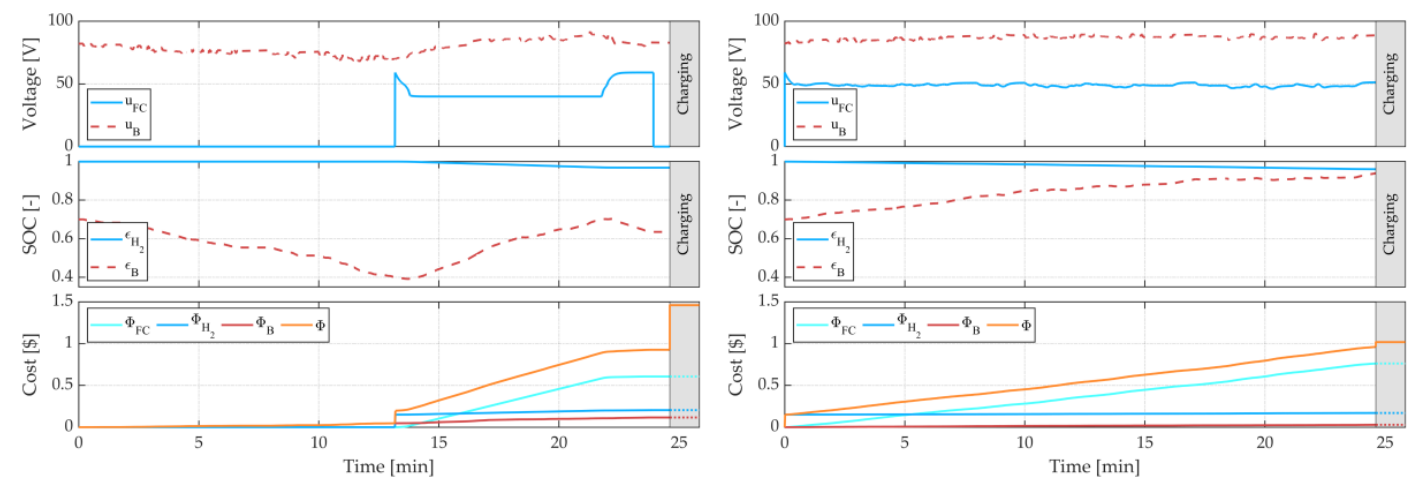

Figure 18. Voltages, state-of-charge and costs achieved over WLTC by H-EMS (left) and S-EMS (right).
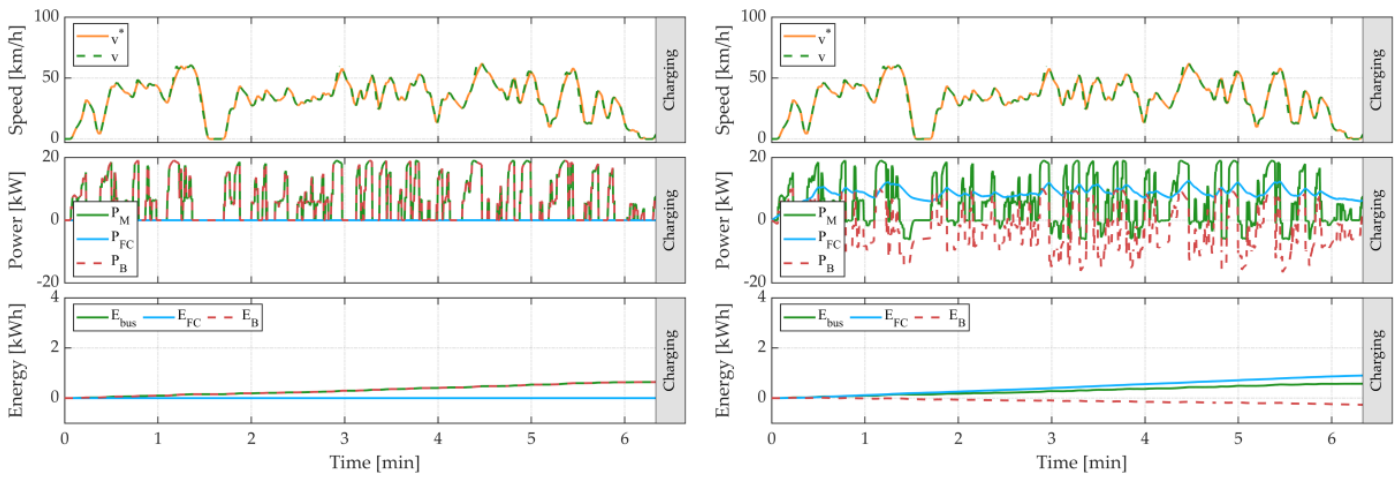

Figure 19. Powers and energies achieved over REAL by H-EMS (left) and S-EMS (right).
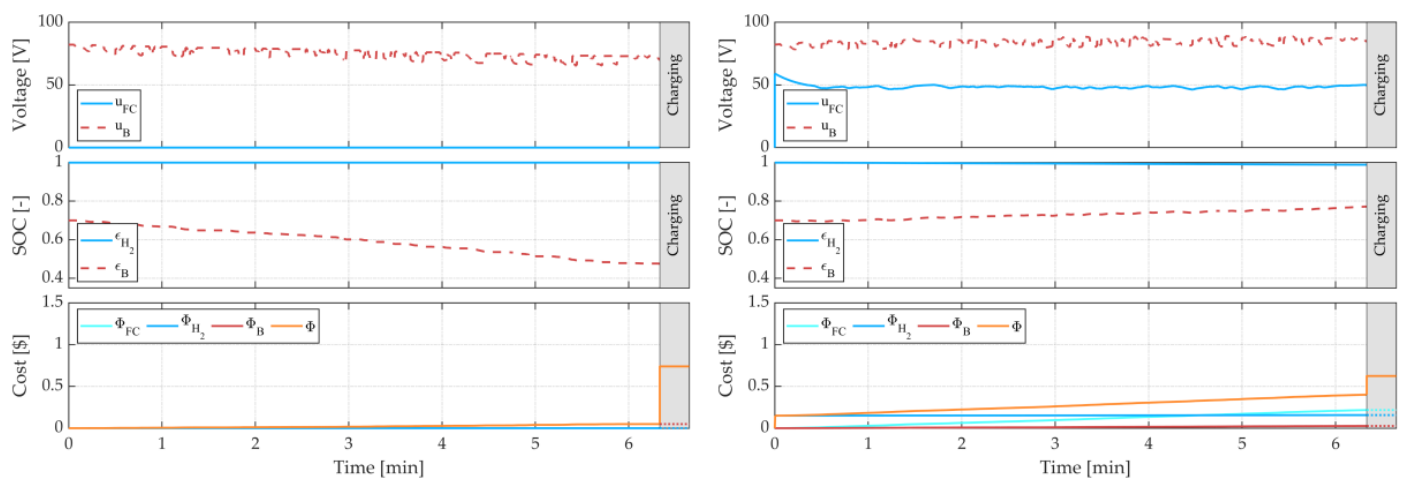

Figure 20. Voltages, state-of-charge and costs achieved over REAL by H-EMS (on the left) and S-EMS (right). 
The values of the cost functions achieved by both H-EMS and S-EMS are summarized in Figure 21 and Table 1. Similarly, the simulation results achieved by A-EMS over different time horizons are summarised in Table 2, together with those of S-EMS for comparison purposes. In this regard, no evolution of voltage, power, energy, state-of-charge and costs are presented for A-EMS because they are nearly the same by S-EMS and, thus, would be weakly informative. Reference is thus made only to the final values of the cost functions in order to assess if and how A-EMS performs better than S-EMS. Based on both Tables 1 and 2, some interesting remarks can be drawn, as reported in the following section.
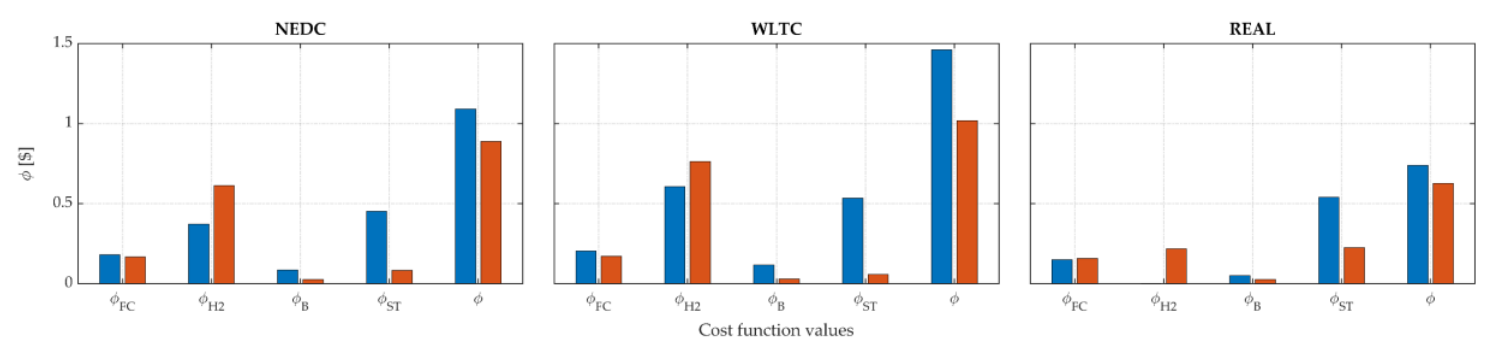

Figure 21. Performance comparison between H-EMS (blue bars) and S-EMS (red bars) in terms of cost function contributions over different driving cycles.

Table 1. Cost function values (H-EMS and S-EMS).

\begin{tabular}{ccccc}
\hline & EMS & NEDC & WLTC & REAL \\
\hline \multirow{2}{*}{$\phi_{\text {FC }}[\$]$} & H-EMS & 0.1812 & 0.2043 & 0.1500 \\
& S-EMS & 0.1665 & 0.1702 & 0.1568 \\
\hline \multirow{2}{*}{$\phi_{H 2}[\$]$} & H-EMS & 0.3720 & 0.6062 & 0.0000 \\
& S-EMS & 0.6131 & 0.7625 & 0.2171 \\
\hline \multirow{2}{*}{$\phi_{\mathrm{B}}[\$]$} & H-EMS & 0.0842 & 0.1162 & 0.0493 \\
& S-EMS & 0.0259 & 0.0286 & 0.0269 \\
\hline \multirow{2}{*}{$\phi_{S T}[\$]$} & H-EMS & 0.4522 & 0.5338 & 0.5405 \\
& S-EMS & 0.0826 & 0.0575 & 0.2240 \\
\hline \multirow{2}{*}{$\Phi[\$]$} & H-EMS & 1.0897 & 1.4605 & 0.7398 \\
& S-EMS & 0.8881 & 1.0187 & 0.6248 \\
\hline
\end{tabular}

Table 2. Cost function values (S-EMS and A-EMS).

\begin{tabular}{|c|c|c|c|c|c|c|c|c|c|c|c|c|c|}
\hline \multirow{2}{*}{$\begin{array}{l}\Delta T \\
{[\mathrm{~s}]}\end{array}$} & \multirow{2}{*}{$\begin{array}{c}\text { Cycle } \\
-\end{array}$} & \multirow{2}{*}{$\begin{array}{c}\text { S-EMS } \\
0\end{array}$} & \multicolumn{11}{|c|}{ A-EMS } \\
\hline & & & 0 & 5 & 20 & 60 & 120 & 180 & 240 & 300 & 60 & 420 & 480 \\
\hline \multirow{3}{*}{$\begin{array}{c}\phi_{\mathrm{FC}} \\
{[\$]}\end{array}$} & & & 01 & & & & & & & 70 & 70 & 71 & 072 \\
\hline & LTC & 0.1702 & 1711 & 1711 & & & & & & & & & \\
\hline & & & & & & & & & & & & & \\
\hline \multirow{3}{*}{$\begin{array}{c}\phi_{H 2} \\
{[\$]}\end{array}$} & & & & & & & & & & & & & \\
\hline & WLTC & 0.76 & 0.7827 & 0.7 & & 0.7 & 0.7 & & & & 03 & & 0.7515 \\
\hline & REAL & 0.2171 & 0.2246 & 0.2243 & 0.2237 & 0.2219 & 0.2192 & 0.2167 & 0.2143 & 0.2121 & 0.2099 & 0.2077 & 0.2056 \\
\hline \multirow{3}{*}{$\begin{array}{l}\phi_{\mathrm{B}} \\
{[\$]}\end{array}$} & 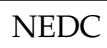 & 0.02 & & & & & & & & & & & \\
\hline & TC & 0.0286 & 0.0 & 1 & 0 & 0.0 & 5 & 00 & 93 & 88 & 82 & 78 & 0.0274 \\
\hline & REAL & 0.0269 & 0.0274 & 0.0274 & 0.0274 & 0.0 & 71 & 0.0269 & & 67 & & 266 & 0.0266 \\
\hline \multirow{3}{*}{$\begin{array}{c}\phi_{S T} \\
{[\$]}\end{array}$} & & & 0.0526 & & & & & & & & & & \\
\hline & WLTC & 0.0575 & 0.0382 & 0.0383 & 0.0385 & 0.0391 & 0.0403 & 0.0441 & 0.0496 & & 0.0602 & 0.0652 & 0.0701 \\
\hline & REAL & 0.2240 & 0.2149 & 0.2152 & 0.2160 & 0.2181 & 0.2212 & 0.2242 & 0.2271 & 0.0230 & 0.2326 & 0.2353 & 0.2379 \\
\hline \multirow{3}{*}{$\begin{array}{c}\Phi \\
{[\$]}\end{array}$} & & 0.00 & & & & & & & & & & & 0.00 \\
\hline & TC & 1.0187 & 1.02 & 1.0 & 26 & 1.0 & & 93 & 91 & & & 1.0192 & $1.01 \mathrm{C}$ \\
\hline & REAL & 0.6248 & 0.6240 & 0.6240 & 0.6240 & 0.6241 & 0.6242 & 0.6244 & 0.6246 & 0.6248 & 0.6251 & 0.6255 & 0.625 \\
\hline
\end{tabular}




\section{Discussion}

The performance comparison of H-EMS and S-EMS highlighted in Figure 21 and Table 1 reveals that S-EMS slightly reduces FC and B degradation costs compared to H-EMS, but significantly increases $\mathrm{H}_{2}$ consumption. However, the additional $\mathrm{H}_{2}$ consumption with S-EMS is more than compensated by the reduction of 'charge sustaining' costs, which leads to lower overall FCBEV operating costs by S-EMS compared to H-EMS for the considered driving cycles. In this regard, the 'charge sustaining' costs represent a significant share of the overall FCBEV operating costs and must be carefully considered in minimising the overall FCBEV cost function. This is the case of S-EMS due to the conversion of the global optimisation problem into an instantaneous problem using (22), specifically by minimising $\varphi$ instead of $\Phi$. Consequently, S-EMS could outperform H-EMS over any driving cycle, revealing its general usefulness.

Considering the comparison of S-EMS and A-EMS, the last rows of Table 2 shows that A-EMS surprisingly achieves worse $\Phi$ minimisation compared to S-EMS in the case of NEDC and WLTC driving cycles, whereas it improves the FCBEV operating performances in the last case (REAL). In particular, A-EMS increases $\mathrm{H}_{2}$ consumption and $\mathrm{B}$ degradation costs compared to S-EMS with the aim of reducing 'charge sustaining' costs further. However, the $\phi_{S T}$ reduction is more than compensated by the cost increase of some of the other $\Phi$ contributions over both the NEDC and WLTC driving cycles, leading to a small but detectable increase in $\Phi$. In this regard, the slightly worse performances achieved by A-EMS are not totally unexpected, especially with respect to the considerations presented in Section 4.1. Since A-EMS tends to increase instantaneous B charging compared to S-EMS, the average $\varepsilon_{B}$ value over each driving cycle of A-EMS is greater than with S-EMS, leading to reduced $\varphi$ minimisation in the upcoming time intervals. This consideration is proved by the fact that A-EMS performances improve as $\triangle T$ increases over both NEDC and WLTC driving cycles, whereas they worsen in the case of the REAL driving cycle, as highlighted in Table 2. If $\varphi$ minimisation accounts for a relatively large upcoming time interval, the increase of $\varepsilon_{\mathrm{B}}$ can be limited because its negative impact on $\Phi$ minimisation can be properly considered. However, this is valid unless too large $\Delta T$ is considered, which prevents $B$ from being charged properly. Furthermore, the assumption that $i_{\mathrm{FC}}$ and $p_{\mathrm{M}}$ are constant over excessively wider time horizons becomes unrealistic, highlighting the need for prior information in order to further improve S-EMS and A-EMS performances.

Despite the above-mentioned issues, the analysis of simulation results reveals very good performances achieved by both S-EMS and A-EMS. Although both S-EMS and A-EMS have been implemented through look-up tables, which have been computed off-line, their relatively simple structure enables them to be performed analytically, without massive computational effort. This feature, which is achieved by converting a global optimisation problem into an instantaneous problem, is particularly attractive, especially with respect to real-time implementation. Consequently, both S-EMS and A-EMS can benefit from updated FCBEV parameter values, which may vary due to different operating conditions and/or ageing effects. In addition, further improvements of A-EMS are possible, on the condition that some prior information on the driving cycle are available.

\section{Conclusions}

Two real-time energy management systems (EMSs) for fuel cell/battery electric vehicles (FCBEVs) were presented and compared. In particular, FCBEV mathematical modelling was first resumed, then a previously presented simplified EMS (S-EMS) [40] was analysed in detail by highlighting its most important strengths and weaknesses. The analysis focused on each contribution of the FCBEV cost function and revealed the need of recharging the battery for maximising the 'charge sustaining' cost reduction. However, the analysis also reveals that relatively high values of the battery state-of-charge may be unsuitable over large time intervals. Therefore, based on these considerations, an advanced EMS (A-EMS) was proposed to overcome the weaknesses of S-EMS, thus ensuring enhanced FCBEV operating cost minimisation. A-EMS is based on more accurate mathematical modelling and considers the minimisation of the FCBEV cost function over an upcoming time 
interval, which would result in improved performances compared to S-EMS. However, numerical simulations highlighted contradictory results depending on the chosen driving cycle. In particular, A-EMS performs slightly worse than S-EMS over relatively long driving cycles due to excessive battery charging, which can be partially prevented by considering relatively long upcoming time intervals, within which A-EMS is able to consider the negative impact of a high battery state-of-charge. Alternatively, A-EMS achieves better optimisation results than S-EMS with a short driving cycle and low battery state-of-charge.

Author Contributions: Conceptualization, A.S. and M.P.; Data curation, A.S. and M.P.; Formal analysis, A.S. and M.P.; Investigation, A.S. and M.P.; Methodology, A.S. and M.P.; Software, A.S. and M.P.; Validation, A.S. and M.P.; Writing—original draft, A.S. and M.P.

Funding: This research received no external funding.

Conflicts of Interest: The authors declare no conflict of interest.

\section{Appendix A}

All the symbols employed throughout the paper are listed in Tables A1 and A2.

Table A1. List of variables.

\begin{tabular}{|c|c|c|c|}
\hline Symbol & Meaning & Value & Unit \\
\hline$u_{\mathrm{FC}}\left(i_{\mathrm{FC}}\right)$ & FC voltage (current) & - & $\mathrm{V}(\mathrm{A})$ \\
\hline$p_{\mathrm{FC}}$ & FC power & - & $\mathrm{W}$ \\
\hline$u_{\mathrm{CH}}\left(i_{\mathrm{CH}}\right)$ & average voltage (current) of the boost converter & - & $\mathrm{V}(\mathrm{A})$ \\
\hline$p_{\mathrm{CH}}$ & average power of the boost converter & - & $\mathrm{W}$ \\
\hline$d$ & duty cycle of the switch $\mathrm{T}$ of the boost converter & - & - \\
\hline$u_{\mathrm{B}}$ & DC-link voltage & - & $\mathrm{V}$ \\
\hline$u_{0}$ & B voltage source & - & $\mathrm{V}$ \\
\hline$i_{\mathrm{B}}\left(\varepsilon_{\mathrm{B}}\right)$ & B current (state-of-charge) & - & A (-) \\
\hline$v_{\mathrm{B}}$ & voltage of the RC branch of $B$ & - & $\mathrm{V}$ \\
\hline$p_{\mathrm{M}}$ & M power at the DC-link & - & W \\
\hline$F_{\mathrm{M}}$ & $\mathrm{M}$ traction effort & - & $\mathrm{N}$ \\
\hline$F_{T}$ & overall traction effort & - & $\mathrm{N}$ \\
\hline$F_{b}$ & braking force & - & $\mathrm{N}$ \\
\hline$k_{D}$ & regenerative braking coefficient & - & - \\
\hline$v$ & vehicle speed & - & $\mathrm{m} / \mathrm{s}$ \\
\hline$n$ & number of FC starts & - & - \\
\hline$\Phi$ & overall cost function & - & $\$$ \\
\hline$\Phi_{0}$ & instantaneous component of $\Phi$ & - & $\$$ \\
\hline$\varphi$ & integrating component of $\Phi$ & - & $\$ / s$ \\
\hline$\phi_{\mathrm{FC}}$ & FC cost function & - & $\$$ \\
\hline$\varphi_{\mathrm{FC}}$ & integrating component of $\phi_{\mathrm{FC}}$ & - & $\$ / \mathrm{s}$ \\
\hline$\phi_{H 2}$ & $\mathrm{H}_{2}$ cost function & - & $\$$ \\
\hline$\varphi_{H 2}$ & integrating component of $\phi_{\mathrm{H} 2}$ & - & $\$ / s$ \\
\hline$\phi_{\mathrm{B}}$ & B cost function & - & $\$$ \\
\hline$\varphi_{\mathrm{B}}$ & integrating component of $\phi_{\mathrm{B}}$ & - & $\$ / \mathrm{s}$ \\
\hline$\phi_{S T}$ & "charge sustaining" cost function & - & $\$$ \\
\hline$\varphi_{S T}$ & integrating component of $\phi_{\mathrm{ST}}$ & - & $\$ / \mathrm{s}$ \\
\hline$\vartheta$ & polar variable of current ellipse & - & rad \\
\hline$\Delta T$ & time interval & - & $\mathrm{s}$ \\
\hline$\psi$ & average value of $\varphi$ within $\Delta \mathrm{T}$ & - & $\$ / s$ \\
\hline
\end{tabular}


Table A2. List of parameters [41].

\begin{tabular}{|c|c|c|c|}
\hline Symbol & Meaning & Value & Unit \\
\hline$a_{0}$ & coefficient of the FC polarization curve & 59.12 & $\mathrm{~V}$ \\
\hline$a_{1}$ & coefficient of the FC polarization curve & -0.119 & $\mathrm{~V} / \mathrm{A}$ \\
\hline$a_{2}$ & coefficient of the FC polarization curve & 0.449 & $\mathrm{mV} / \mathrm{A}^{2}$ \\
\hline$a_{3}$ & coefficient of the FC polarization curve & -0.678 & $\mu \mathrm{V} / \mathrm{A}^{3}$ \\
\hline$r_{L}(L)$ & resistance (inductance) of the boost converter & - & $\Omega(\mathrm{H})$ \\
\hline$\gamma_{0}$ & coefficient of the $\mathrm{H}_{2}$ consumption curve & 23.7 & $\mathrm{~g} / \mathrm{s}$ \\
\hline$\gamma_{1}$ & coefficient of the $\mathrm{H}_{2}$ consumption curve & 0.786 & $\mathrm{~g} / \mathrm{s} / \mathrm{A}$ \\
\hline$\eta_{\mathrm{ch}}$ & average efficiency of the boost converter & 0.95 & - \\
\hline$\mu_{0}$ & coefficient of the B voltage source curve & 74.0829 & $\mathrm{~V}$ \\
\hline$\mu_{1}$ & coefficient of the B voltage source curve & 11.4857 & $\mathrm{~V}$ \\
\hline$r_{s}$ & B series resistance & 28 & $\mathrm{~m} \Omega$ \\
\hline$r_{C}, C$ & resistance and capacitance of the $\mathrm{RC}$ branch of $\mathrm{B}$ & $141.7(3529.4)$ & $\mathrm{m} \Omega(\mathrm{F})$ \\
\hline$Q_{\mathrm{B}}$ & B rated capacity & 40 & $\mathrm{Ah}$ \\
\hline$\tilde{\eta_{\mathrm{M}}}$ & M efficiency & - & - \\
\hline$\xi_{M}, \varsigma_{M}$ & efficiency-based M coefficients & - & - \\
\hline $\mathcal{C}_{\mathrm{FC}}$ & FC specific cost & 600 & $\$$ \\
\hline$\Delta_{\mathrm{FC}}$ & FC start-stop coefficient & $2.5 \cdot 10^{-4}$ & - \\
\hline$k_{\mathrm{FC}}$ & FC load coefficient & $1.3889 \cdot 10^{-8}$ & $\mathrm{~s}^{-1}$ \\
\hline$\alpha$ & FC load coefficient & 4 & - \\
\hline$P_{\mathrm{FC}}$ & FC rated power & 6 & $\mathrm{~kW}$ \\
\hline$c_{H 2}$ & Hydrogen cost & $3.5 \cdot 10^{-3}$ & $\$ / g$ \\
\hline$c_{\mathrm{B}}$ & B specific cost & 640 & $\$$ \\
\hline$k_{\mathrm{B}}$ & B load coefficient & $4.6296 \cdot 10^{-10}$ & $C^{-1}$ \\
\hline$I_{\mathrm{B}}$ & $\mathrm{B}$ rated current & 40 & A \\
\hline$p_{3}$ & "charge sustaining" coefficient & -0.0286 & $\$$ \\
\hline$p_{2}$ & "charge sustaining" coefficient & 0.2527 & $\$$ \\
\hline$p_{1}$ & "charge sustaining" coefficient & -1.3620 & $\$$ \\
\hline$p_{0}$ & "charge sustaining" coefficient & 1.1376 & $\$$ \\
\hline$a_{\mathrm{FC}}$ & gain coefficient of current ellipse & - & $\Omega^{\frac{1}{2}}$ \\
\hline$a_{\mathrm{B}}$ & gain coefficient of current ellipse & - & $\Omega^{\frac{1}{2}}$ \\
\hline$c_{\mathrm{FC}}$ & $\mathrm{i}_{\mathrm{FC}}$-axis component of current ellipse center & - & A \\
\hline$c_{\mathrm{B}}$ & $\mathrm{i}_{\mathrm{B}}$-axis component of current ellipse center & - & A \\
\hline$r$ & equivalent radius of current ellipse & - & $\mathrm{A} / \Omega^{\frac{1}{2}}$ \\
\hline$b_{1}$ & coefficient of the $i_{B}-i_{F C}$ relationship & - & A \\
\hline$b_{0}$ & coefficient of the $i_{B}-i_{F C}$ relationship & - & $A^{2}$ \\
\hline
\end{tabular}

\section{References}

1. Ehsani, M.; Gao, Y.; Emadi, A. Modern Electric, Hybrid. Electric, and Fuel Cell Vehicles: Fundamentals, Theory, and Design, 2nd ed.; CRC Press: Boca Raton, FL, USA, 2009; ISBN 978-1-4200-5400-2.

2. Das, H.S.; Tan, C.W.; Yatim, A.H.M. Fuel cell hybrid electric vehicles: A review on power conditioning units and topologies. Renew. Sustain. Energy Rev. 2017, 76, 268-291. [CrossRef]

3. Gurz, M.; Baltacioglu, E.; Hames, Y.; Kaya, K. The meeting of hydrogen and automotive: A review. Int. J. Hydrogen Energy 2017, 42, 23334-23346. [CrossRef]

4. Xun, Q.; Liu, Y.; Holmberg, E. A Comparative Study of Fuel Cell Electric Vehicles Hybridization with Battery or Supercapacitor. In Proceedings of the 2018 International Symposium on Power Electronics, Electrical Drives, Automation and Motion (SPEEDAM), Amalfi, Italy, 20-22 June 2018; pp. 389-394.

5. Hemmati, R.; Saboori, H. Emergence of hybrid energy storage systems in renewable energy and transport applications-A review. Renew. Sustain. Energy Rev. 2016, 65, 11-23. [CrossRef]

6. Sulaiman, N.; Hannan, M.A.; Mohamed, A.; Majlan, E.H.; Wan Daud, W.R. A review on energy management system for fuel cell hybrid electric vehicle: Issues and challenges. Renew. Sustain. Energy Rev. 2015, 52, 802-814. [CrossRef]

7. Feroldi, D.; Carignano, M. Sizing for fuel cell/supercapacitor hybrid vehicles based on stochastic driving cycles. Appl. Energy 2016, 183, 645-658. [CrossRef] 
8. Xu, L.; Mueller, C.D.; Li, J.; Ouyang, M.; Hu, Z. Multi-objective component sizing based on optimal energy management strategy of fuel cell electric vehicles. Appl. Energy 2015, 157, 664-674. [CrossRef]

9. Xu, L.; Ouyang, M.; Li, J.; Yang, F.; Lu, L.; Hua, J. Optimal sizing of plug-in fuel cell electric vehicles using models of vehicle performance and system cost. Appl. Energy 2013, 103, 477-487. [CrossRef]

10. Sampietro, J.L.; Puig, V.; Costa-Castelló, R. Optimal Sizing of Storage Elements for a Vehicle Based on Fuel Cells, Supercapacitors, and Batteries. Energies 2019, 12, 925. [CrossRef]

11. Wang, L.; Collins, E.G., Jr.; Li, H. Optimal Design and Real-Time Control for Energy Management in Electric Vehicles. IEEE Trans. Veh. Technol. 2011, 60, 1419-1429. [CrossRef]

12. Livint, G.; Stan, A.G. Control strategies for hybrid electric vehicles with two energy sources on board. In Proceedings of the International Conference and Exposition on Electrical and Power Engineering (EPE 2014), Iasi, Romania, 16-18 October 2014; pp. 142-147.

13. Zhang, T.; Wang, P.; Chen, H.; Pei, P. A review of automotive proton exchange membrane fuel cell degradation under start-stop operating condition. Appl. Energy 2018, 223, 249-262. [CrossRef]

14. Sulaiman, N.; Hannan, M.A.; Mohamed, A.; Ker, P.J.; Majlan, E.H.; Wan Daud, W.R. Optimization of energy management system for fuel-cell hybrid electric vehicles: Issues and recommendations. Appl. Energy 2018, 228, 2061-2079. [CrossRef]

15. Li, X.; Li, J.; Xu, L.; Ouyang, M. Power management and economic estimation of fuel cell hybrid vehicle using fuzzy logic. In Proceedings of the 5th IEEE Vehicle Power and Propulsion Conference (VPPC 2009), Dearborn, MI, USA, 7-10 September 2009; pp. 1749-1754.

16. Ravey, A.; Mohammadi, A.; Bouquain, D. Control strategy of fuel cell electric vehicle including degradation process. In Proceedings of the 41st Annual Conference of the IEEE Industrial Electronics Society (IECON 2015), Yokohama, Japan, 9-12 November 2015; pp. 003508-003513.

17. Jawadi, S.; Slama, S.B.; Zafar, B.; Cherif, A. An efficient control strategy for hybrid PEMFC/Supercapacitor power source applied for automotive application. In Proceedings of the 16th International Conference on Sciences and Techniques of Automatic Control and Computer Engineering (STA 2015), Monastir, Tunisia, 21-23 December 2015; pp. 432-437.

18. Kaya, K.; Hames, Y. Two new control strategies: For hydrogen fuel saving and extend the life cycle in the hydrogen fuel cell vehicles. Int. J. Hydrogen Energy 2019, 44, 18967-18980. [CrossRef]

19. Weyers, C.; Bocklisch, T. Simulation-based investigation of energy management concepts for fuel cell-battery-hybrid energy storage systems in mobile applications. Energy Procedia 2018, 155, 295-308. [CrossRef]

20. Marzougui, H.; Kadri, A.; Amari, M.; Bacha, F. Frequency separation based energy management strategy for fuel cell electrical vehicle with super-capacitor storage system. In Proceedings of the 9th International Renewable Energy Congress (IREC 2018), Hammamet, Tunisia, 20-22 March 2018; pp. 1-6.

21. Tani, A.; Camara, M.B.; Dakyo, B. Energy Management Based on Frequency Approach for Hybrid Electric Vehicle Applications: Fuel-Cell/Lithium-Battery and Ultracapacitors. IEEE Trans. Veh. Technol. 2012, 61, 3375-3386. [CrossRef]

22. Badji, A.; Abdeslam, D.O.; Becherif, M.; Eltoumi, F.; Benamrouche, N. Analyze and evaluate of energy management system for fuel cell electric vehicle based on frequency splitting. Math. Comput. Simul. 2019, 167, 65-77. [CrossRef]

23. Ettihir, K.; Boulon, L.; Agbossou, K. Energy management strategy for a fuel cell hybrid vehicle based on maximum efficiency and maximum power identification. IET Electr. Syst. Transp. 2016, 6, 261-268. [CrossRef]

24. Pregelj, B.; Micor, M.; Dolanc, G.; Petrovčič, J.; Jovan, V. Impact of fuel cell and battery size to overall system performance-A diesel fuel-cell APU case study. Appl. Energy 2016, 182, 365-375. [CrossRef]

25. Zhang, H.; Li, X.; Liu, X.; Yan, J. Enhancing fuel cell durability for fuel cell plug-in hybrid electric vehicles through strategic power management. Appl. Energy 2019, 241, 483-490. [CrossRef]

26. Bizon, N. Energy optimization of fuel cell system by using global extremum seeking algorithm. Appl. Energy 2017, 206, 458-474. [CrossRef]

27. Li, H.; Ravey, A.; N’Diaye, A.; Djerdir, A. A novel equivalent consumption minimization strategy for hybrid electric vehicle powered by fuel cell, battery and supercapacitor. J. Power Sources 2018, 395, 262-270. [CrossRef] 
28. Cheng, G.; Hao, L.; Xinbo, C.; Shaoming, Q. Parameter design of the powertrain of fuel cell electric vehicle and the energy management strategy. In Proceedings of the 34th Chinese Control Conference (CCC 2015), Hangzhou, China, 28-30 July 2015; pp. 8027-8032.

29. Wang, Y.; Moura, S.J.; Advani, S.G.; Prasad, A.K. Power management system for a fuel cell/battery hybrid vehicle incorporating fuel cell and battery degradation. Int. J. Hydrogen Energy 2019, 44, 8479-8492. [CrossRef]

30. Jiang, H.; Xu, L.; Li, J.; Hu, Z.; Ouyang, M. Energy management and component sizing for a fuel cell/battery/supercapacitor hybrid powertrain based on two-dimensional optimization algorithms. Energy 2019, 177, 386-396. [CrossRef]

31. Bambang, R.T.; Rohman, A.S.; Dronkers, C.J.; Ortega, R.; Sasongko, A. Energy Management of Fuel Cell/Battery/Supercapacitor Hybrid Power Sources Using Model Predictive Control. IEEE Trans. Ind. Inform. 2014, 10, 1992-2002.

32. da Fonseca, R.; Bideaux, E.; Jeanneret, B.; Gerard, M.; Desbois-Renaudin, M.; Sari, A. Energy management strategy for hybrid fuel cell vehicle. In Proceedings of the 12th International Conference on Control, Automation and Systems (ICCAS 2012), Jeju Island, Korea, 17-21 October 2012; pp. 485-490.

33. Tribioli, L.; Cozzolino, R.; Chiappini, D.; Iora, P. Energy management of a plug-in fuel cell/battery hybrid vehicle with on-board fuel processing. Appl. Energy 2016, 184, 140-154. [CrossRef]

34. Gaoua, Y.; Caux, S.; Lopez, P.; Raga, C.; Barrado, A.; Lazaro, A. Hybrid Systems Energy Management Using Optimization Method Based on Dynamic Sources Models. In Proceedings of the 10th IEEE Vehicle Power and Propulsion Conference (VPPC 2014), Coimbra, Portugal, 27-30 October 2014; pp. 1-6.

35. Li, H.; Ravey, A.; N’Diaye, A.; Djerdir, A. Equivalent consumption minimization strategy for hybrid electric vehicle powered by fuel cell, battery and supercapacitor. In Proceedings of the 42nd Annual Conference of the IEEE Industrial Electronics Society (IECON 2016), Florence, Italy, 23-26 October 2016; pp. 4401-4406.

36. Morales-Morales, J.; Cervantes, I.; Cano-Castillo, U. On the Design of Robust Energy Management Strategies for FCHEV. IEEE Trans. Veh. Technol. 2015, 64, 1716-1728. [CrossRef]

37. Serpi, A.; Porru, M.; Damiano, A. An Optimal Power and Energy Management by Hybrid Energy Storage Systems in Microgrids. Energies 2017, 10, 1909. [CrossRef]

38. Weitzel, T.; Glock, C.H. Energy management for stationary electric energy storage systems: A systematic literature review. Eur. J. Oper. Res. 2018, 264, 582-606. [CrossRef]

39. Agüera-Pérez, A.; Palomares-Salas, J.C.; González de la Rosa, J.J.; Florencias-Oliveros, O. Weather forecasts for microgrid energy management: Review, discussion and recommendations. Appl. Energy 2018, 228, 265-278. [CrossRef]

40. Serpi, A.; Porru, M. A Real-Time Energy Management System for Operating Cost Minimization of Fuel Cell/Battery Electric Vehicles. In Proceedings of the 13th IEEE Vehicle Power and Propulsion Conference (VPPC 2017), Belfort, France, 11-14 December 2017; pp. 1-5.

41. Depature, C.; Jemei, S.; Boulon, L.; Bouscayrol, A.; Marx, N.; Morando, S.; Castaings, A. IEEE VTS Motor Vehicles Challenge 2017-Energy Management of a Fuel Cell/Battery Vehicle. In Proceedings of the Proc. of 12nd IEEE Vehicle Power and Propulsion Conference (VPPC 2016), Hangzhou, China, 17-20 October 2016; pp. 1-6.

42. Depature, C.; Jemei, S.; Boulon, L.; Bouscayrol, A.; Marx, N.; Morando, S.; Castaings, A. Energy Management in Fuel-Cell $\backslash$ Battery Vehicles: Key Issues Identified in the IEEE Vehicular Technology Society Motor Vehicle Challenge 2017. IEEE Vehicular Technol. Mag. 2018, 13, 144-151. [CrossRef]

(C) 2019 by the authors. Licensee MDPI, Basel, Switzerland. This article is an open access article distributed under the terms and conditions of the Creative Commons Attribution (CC BY) license (http://creativecommons.org/licenses/by/4.0/). 